\title{
Functional trait variation related to gap dynamics in tropical moist forests: a vegetation modelling perspective
}

Article

Accepted Version

Creative Commons: Attribution-Noncommercial-No Derivative Works 4.0

Togashi, H. F., Atkin, O. K., Bloomfield, K. J., Bradford, M., Cao, K., Dong, N., Evans, B. J., Fan, Z., Harrison, S. P., Hua, Z., Liddell, M. J., Lloyd, J., Ni, J., Wang, H., Weerasinghe, L. K. and Prentice, I. C. (2018) Functional trait variation related to gap dynamics in tropical moist forests: a vegetation modelling perspective. Perspectives in Plant Ecology, Evolution and Systematics, 35. pp. 52-64. ISSN 1433-8319 doi:

https://doi.org/10.1016/j.ppees.2018.10.004 Available at https://centaur.reading.ac.uk/80295/

It is advisable to refer to the publisher's version if you intend to cite from the work. See Guidance on citing.

To link to this article DOI: http://dx.doi.org/10.1016/j.ppees.2018.10.004

Publisher: Elsevier

All outputs in CentAUR are protected by Intellectual Property Rights law, including copyright law. Copyright and IPR is retained by the creators or other copyright holders. Terms and conditions for use of this material are defined in the End User Agreement. 


\section{www.reading.ac.uk/centaur}

\section{CentAUR}

Central Archive at the University of Reading

Reading's research outputs online 
1 Functional trait variation related to gap dynamics in tropical moist forests: a vegetation modelling perspective

4 Henrique Fürstenau Togashi ${ }^{\mathrm{a}, \mathrm{b}, *}$, Owen K. Atkin ${ }^{\mathrm{c}, \mathrm{d}}$, Keith J. Bloomfield ${ }^{\mathrm{c}}$, Matt 5 Bradford $^{\mathrm{e}}$, Kunfang Cao ${ }^{\mathrm{f}}$, Ning Dong ${ }^{\mathrm{a}, \mathrm{b}, \mathrm{g}}$, Bradley J. Evans ${ }^{\mathrm{a}, \mathrm{b}}$, Zexin Fan ${ }^{\mathrm{h}}$, Sandy P. 6 Harrison $^{\mathrm{a}, \mathrm{g}}$, Zhu Hua ${ }^{\mathrm{h}}$, Michael J. Liddell, Jon Lloyd ${ }^{\mathrm{i}, \mathrm{j}}$, Jian Ni ${ }^{\mathrm{k}, \mathrm{l}}$, Han Wang ${ }^{\mathrm{a}, \mathrm{m}}$, 7 Lasantha K. Weerasinghe ${ }^{c, n}$, Iain Colin Prentice ${ }^{\mathrm{a}, \mathrm{j}, \mathrm{m}, \mathrm{o}}$

aDepartment of Biological Sciences, Macquarie University, North Ryde, NSW 2109, Australia

$11{ }^{\mathrm{b}}$ The Ecosystem Modelling and Scaling Infrastructure Facility (eMAST), Faculty of 12 Agriculture and Environment, Department of Environmental Sciences, The University 13 of Sydney, NSW 2006, Australia

14 'Division of Plant Sciences, Research School of Biology, Australian National University, Canberra, ACT 2601, Australia

${ }^{\mathrm{d} A R C}$ Centre of Excellence in Plant Energy Biology, Research School of Biology, Australian National University, Canberra, ACT 2601, Australia

${ }^{\mathrm{e} C o m m o n w e a l t h ~ S c i e n c e ~ a n d ~ I n d u s t r i a l ~ R e s e a r c h ~ O r g a n i z a t i o n ~(C S I R O), ~ T r o p i c a l ~}$ Forest Research Centre, Atherton, Queensland 4883, Australia

20 State Key Laboratory of Conservation and Utilization of Subtropical Agro21 bioresources, College of Forestry, Guangxi University, Daxuedonglu 100, Nanning 22 530005, Guangxi, China

$23{ }^{\mathrm{g}}$ School of Archaeology, Geography and Environmental Sciences, University of 24 Reading, Whiteknights, Reading RG6 6AB, UK

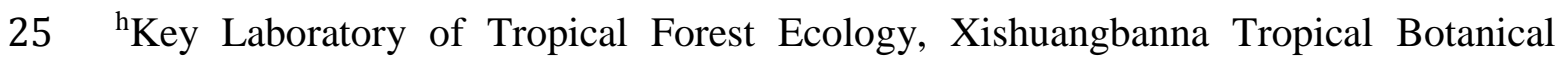
26 Garden, Chinese Academy of Sciences, Menglun, Mengla, Yunnan 666303, China

$27{ }^{i}$ Centre for Tropical Environmental and Sustainability Science (TESS) and College of 28 Science, Technology and Engineering, James Cook University, Cairns, Queensland 29 4878, Australia

30 jDepartment of Life Sciences, Imperial College London, Silwood Park Campus, 31 Buckhurst Road, Ascot SL5 7PY, UK

$32{ }^{\mathrm{k}}$ State Key Laboratory of Environmental Geochemsitry, 99 Lincheng West Road, 33 Guanshanhu, Guiyang, Guizhou 550081, China 
$34{ }^{\mathrm{l} C o l l e g e}$ of Chemistry and Life Sciences, Zhejiang Normal University, Yingbin 35 Avenue 688, Jinhua 321004, Zhejiang, China ${ }^{\mathrm{m}}$ Department of Earth System Science, Tsinghua University, Beijing 100084, China ${ }^{\mathrm{n}}$ Faculty of Agriculture, University of Peradeniya, Peradeniya 20400, Sri Lanka ${ }^{\text {o}}$ State Key Laboratory of Soil Erosion and Dryland Farming on the Loess Plateau, College of Forestry, Northwest Agriculture \& Forestry University, Yangling 712100, China

*Corresponding author (henriquetogashi@gmail.com)

\section{ABSTRACT}

The conventional representation of Plant Functional Types (PFTs) in Dynamic Global Vegetation Models (DGVMs) is increasingly recognized as simplistic and lacking in predictive power. Key ecophysiological traits, including photosynthetic parameters, are typically assigned single values for each PFT while the substantial trait variation within PFTs is neglected. This includes continuous variation in response to environmental factors, and differences linked to spatial and temporal niche differentiation within communities. A much stronger empirical basis is required for the treatment of continuous plant functional trait variation in DGVMs. We analyse 431 sets of measurements of leaf and plant traits, including photosynthetic measurements, on evergreen angiosperm trees in tropical moist forests of Australia and China. Confining attention to tropical moist forests, our analysis identifies trait differences that are linked to vegetation dynamic roles. Coordination theory predicts that Rubisco- and electron-transport limited rates of photosynthesis are co-limiting under field conditions. The least-cost hypothesis predicts that air-to-leaf $\mathrm{CO}_{2}$ drawdown minimizes the combined costs per unit carbon assimilation of maintaining carboxylation and transpiration capacities. Aspects of these predictions are supported

61 for within-community trait variation linked to canopy position, just as they are for

62 variation along spatial environmental gradients. Trait differences among plant species occupying different structural and temporal niches may provide a basis for the ecophysiological representation of vegetation dynamics in next-generation DGVMs. 


\section{Introduction}

The development of Dynamic Global Vegetation Models (DGVMs) from the earliest stages has emphasized the role of the distribution of different types of plants and vegetation in predicting the exchanges of carbon between the atmosphere and the land biota (Prentice et al., 2007; Prentice and Cowling, 2013). Plant Functional Type (PFT) classifications can be traced back to the Raunkiær's (1934) 'life form' classification, based on plant traits that ensure persistence through seasons unfavourable for growth (Harrison et al., 2010). After several decades during which plant functional geography was neglected, new PFT classifications appeared during the 1980s (Box, 1981; Woodward, 1987) with a view to the development of DGVMs - which began in earnest during the late 1980s. The PFT concept has received significant attention since then (Prentice et al., 1992; Díaz and Cabido, 1997; Lavorel and Garnier, 2002; Wright et al., 2004; Prentice et al., 2007; Harrison et al., 2010; Fyllas et al., 2012). It has become widely accepted that PFT classifications for modelling purposes ideally should reflect aspects of trait diversity that can predict plant responses to the physical environment.

PFTs adopted in DGVMs today are commonly defined in terms of up to five qualitative traits: (a) life form, (b) leaf type, (c) phenological type, (d) photosynthetic pathway and (e) climatic range defined in terms of broad climatic classes such as 'boreal' and 'tropical'. This conventional approach to PFT classification has manifold limitations (Prentice and Cowling, 2013). For example, life-forms are often incompletely defined in functional terms. Informal and potentially ambiguous terms such as 'shrub' have been used in place of Raunkiær's explicit functional categories. Leaf-type definitions usually ignore the huge variations in leaf size and shape among 'broad-leaved' plants. Even the distinction between broad and needle-leaved trees is often effectively an imperfect surrogate for the important distinction in hydraulic architecture between angiosperms and gymnosperms - the latter, in fact, including many species with broad leaves. Thermal climate categories may make sense if they are recognized as a surrogate for different cold-tolerance mechanisms in phanerophytes (Prentice et al., 1992). Harrison et al. (2010) provided a more recent compilation of experimental data on cold tolerance. However, such categories are often used without clear definitions. They may stand in for a continuum of physiological differences between plants adapted or acclimated to different seasonal 
temperature regimes, rather than representing qualitative differences among distinct types of plant. Moreover, thermal climate categories may artificially restrict modelled PFT distributions within confined areas even if the absence of a given PFT from a wider area could be due to competitive exclusion by other types. Ideally, shifts of dominance in models should not be imposed in this way, but should emerge naturally through competitive advantage (Fisher et al., 2015).

A distinct aspect of plant functional classification pertains to species' 'roles' in vegetation dynamics. Classifications of tree species according to shade tolerance (Whitmore, 1982), growth characteristics: maximum height and growth rate (Shugart, 1984; Swaine and Whitmore, 1988) and successional stage (pioneer versus climax) Swaine and Whitmore (1988) have been a mainstay of regionally specific 'gap models' designed to predict forest dynamics under constant or changing environmental conditions (Botkin et al., 1972; Shugart, 1984; Denslow, 1987; Prentice and Leemans, 1990; Prentice et al., 1993; Turner, 2001) but are not treated by most DGVMs. Exceptions are those models with individual-based dynamical cores, such as LPJ-GUESS (Smith et al., 2001), Hybrid (Friend et al., 1993), ED (Moorcroft et al., 2001; Medvigy et al., 2009), aDGVM2 (Langan et al., 2017), and models that make use of the Perfect Plasticity Approximation (PPA). PPA is a mathematical approach designed to represent the essentials of forest dynamics without simulating individual trees explicitly (Purves et al., 2008; Fyllas et al., 2014; Fisher et al., 2015).

A general critique of the use of PFTs for modelling purposes has emerged with the development of new dynamic vegetation models based on continuous trait variation (Pavlick et al., 2013; Scheiter et al., 2013; Verheijen et al., 2013; Fyllas et al., 2014; van Bodegom et al., 2014; Sakschewski et al., 2015), raising a question as to whether distinct PFTs are necessary for modelling vegetation. In our view there is a clear-cut case for retaining the well-understood distinctions among photosynthetic pathways, and there may also be good reasons also to retain life-form distinctions - at least at the highest level of Raunkiær's classification. However, most quantitative traits show continuous adaptive variation along environmental gradients (Meng et al., 2015), indicating that the conventional approach of assigning fixed values of leaflevel traits such as carboxylation capacity $\left(V_{\mathrm{cmax}}\right)$ and nitrogen content per unit leaf area ( $\left.N_{\text {area }}\right)$ to PFTs does not adequately describe the plasticity of such traits within species (phenotypic plasticity). Even biophysical traits such as leaf mass per area 
134 (LMA) and leaf dry-matter content, which are typically less plastic than metabolic 135 traits (Meng et al., 2015; Dong et al., 2017), show systematic, quantitative variations 136 along environmental gradients, partly as a consequence of species turnover within 137 PFTs and thus not necessarily the replacement of one PFT by another. Faced with 138 continuous trait variation (due to species or genotypic turnover and/or phenotypic 139 plasticity), models can either treat it as continuous - as the LPJ DGVM (Sitch et al., 140 2003) does for photosynthetic traits, following the approach developed by Haxeltine 141 and Prentice (1996) - or subdivide the continuum into arbitrary sections. However, 142 problems such as unrealistically abrupt modelled vegetation transitions can arise if the 143 subdivision of the continuum is too coarse, suggesting that a continuous 144 representation will be more useful.

145 This paper describes an empirical analysis that is oriented towards the 146 improvement of DGVMs. Our primary focus is on the largely neglected 'dynamical' 147 aspect of PFT classification. We adopt the fourfold scheme introduced by Shugart 148 (1984) as an initial scheme to classify species' dynamic roles. We recognize that this 149 classification represents a subdivision of two orthogonal continua of variation: shade 150 tolerance (requiring, versus not requiring, a gap for regeneration) and size at maturity 151 (producing, versus not producing, a gap upon mortality). We focus on functional trait 152 variations within tropical moist forests, which harbour enormous tree species diversity 153 and contain species that exhibit all combinations of these traits (Turner, 2001). We 154 build on a previous analysis by Fyllas et al. (2012), who showed that quantitative 155 traits including foliar $\delta^{13} \mathrm{C}$ discrimination, LMA and nutrients including $\mathrm{N}$ and $\mathrm{P}$ 156 could be used to discriminate PFTs with distinct dynamic characteristics in 157 Amazonian rain forests. Our analysis focuses on east Asian (SW China) and northern 158 Australian tropical rain forests, and extends the approach of Fyllas et al. (2012) to 159 include field photosynthetic measurements.

160 Theory and Principles

161 Recent empirical analyses aiming to inform the development of 'next162 generation' DGVMs have focused on the predictability of key quantitative traits as a 163 function of environmental variation (Yang et al., 2018). The 'least-cost' (Prentice et 164 al., 2014) and 'coordination' (Maire et al., 2012) hypotheses together suggest a degree 165 of predictability for the air-to-leaf $\mathrm{CO}_{2}$ drawdown $(\chi$, the ratio of leaf-internal to 
166 ambient $\mathrm{CO}_{2}$ ) (Prentice et al., 2014; Wang et al., 2017), $V_{\mathrm{cmax}}$ and the electron167 transport capacity $J_{\max }$ (Togashi et al., 2017), and $N_{\text {area }}$ (Dong et al., 2017) across 168 environments and clades. Both hypotheses have a much longer pedigree than 169 indicated by the recent references cited here, but systematic testing of these 170 hypotheses has only been undertaken quite recently.

171 The least-cost hypothesis proposes that at the leaf level, plants should respond 172 to differences in the relative costs (per unit of assimilation achieved) of maintaining 173 the biochemical capacity for photosynthesis versus the structural capacity for 174 transpiration by making an optimal investment 'decision' that minimizes the total 175 carbon cost of maintaining both essential functions. This hypothesis can be shown to 176 lead to an optimum value of $\chi$ that depends predictably on temperature, vapour 177 pressure deficit and atmospheric pressure (Prentice et al., 2014; Wang et al., 2017). 178 The mathematical expression of this optimum value includes a parameter that is 179 influenced by low plant-available moisture, and therefore by soil moisture and rooting 180 characteristics (Zhou et al., 2013). This optimum has the same mathematical form as 181 that predicted approximately by the Cowan-Farquhar optimality criterion for electron182 transport limited photosynthesis. This form is known to provide good predictions of 183 stomatal behaviour under a range of conditions (Medlyn et al., 2011; Lin et al., 2015; 184 Dewar et al., 2018). The least-cost hypothesis however is more explicit than the 185 Cowan-Farquhar criterion in that it 'unpacks' water transport and biochemical costs, and assigns to each of them an explicit ecophysiological meaning.

The coordination hypothesis indicates that under typical daytime conditions, 188 the Rubisco-limited and electron transport-limited rates of photosynthesis should be 189 approximately equal (Chen et al., 1993; Haxeltine and Prentice, 1996; Maire et al., 190 2012). This represents the optimal disposition of resources between light capture and 191 carbon fixation. It leads to the prediction that the outer-canopy $V_{\text {cmax }}$ measured at the 192 prevailing growth temperature should be determined by $\chi$ (higher values of one 193 quantity are consistent with lower values of the other), temperature (higher $V_{\mathrm{cmax}}$ is 194 required to achieve a given assimilation rate at higher temperatures), and incident 195 photosynthetically active radiation (PAR) (productive investment in $V_{\text {cmax }}$ is directly 196 proportional to the available PAR) (Dong et al., 2017). $N_{\text {area }}$ is generally found to be 197 roughly linearly related to Rubisco content, and thus to $V_{\mathrm{cmax}}$ at standard temperature. 198 However, leaf $\mathrm{N}$ also has structural and defensive components that are roughly 199 proportional to LMA and represent a largely independent source of variation in $N_{\text {area }}$ 
200 (Dong et al., 2017). So far, these predictions have been supported for seasonal 201 variations within individual plants (Togashi et al., 2017), and for spatial variations 202 along environmental gradients (Prentice et al., 2014; Dong et al., 2017). Here we 203 extend their application to biotically conditioned, microenvironmental variation 204 within forest environments. The framework provided by the least-cost and 205 coordination hypotheses suggest moreover that shade tolerance, and stem properties 206 such as height and wood density, should also be related to leaf metabolic and 207 structural traits, as proposed by Whitehead et al. (1984) and many later commentators. 208 The least-cost and coordination hypotheses are optimality concepts, whose 209 rationale depends on the heuristic principle that natural selection is expected to have 210 eliminated all trait combinations that fall short of optimality according to some 211 specified criterion. Another optimality concept lies behind the Leaf Economics 212 Spectrum, LES (Wright et al., 2004). Fundamentally, the LES represents a universal 213 negative correlation between LMA and leaf life-span (Lloyd et al., 2013), which can 214 be considered to arise from a trade-off because (a) carbon available for investment in 215 leaves is limited and (b) long-lived leaves need to be thicker and/or tougher than 216 short-lived leaves in order to avoid high risks of predation by herbivores and other 217 kinds of mechanical damage. Thus leaves can be short-lived and flimsy or long-lived 218 and thick and/or tough, or somewhere in between. In contrast, short-lived leaves with 219 high LMA would be uneconomic, while long-lived leaves with low LMA would be 220 unviable.

221 In this study we consider four groups of leaf and stem traits. The first group 222 consists of leaf metabolic traits: $V_{\text {cmax }}, J_{\max }$ and leaf dark respiration $\left(R_{\text {dark }}\right)$, which has 223 been found to correlate with $V_{\text {cmax }}$ (Atkin et al., 2000; Weerasinghe et al., 2014). The 224 second group contains the leaf structural/chemical traits $N_{\text {area}}, P_{\text {area }}$ and LMA. As 225 previously noted, $N_{\text {area }}$ has a metabolic component as well as a structural component, 226 and the same may be true for $P_{\text {area }}$ (Evans, 1989; Reich et al., 1997; Fyllas et al., 227 2009). But increasing evidence points to the dominance of the structural component 228 when large sets of species are considered (Dong et al., 2017; Yang et al., 2018). The 229 third group, represented principally by wood density (WD), stands in for plant 230 hydraulics: denser wood tends to have lower permeability to water (Sperry, 2003; Lin 231 et al., 2015). Wood density also directly influences plant growth because volume 232 growth is necessarily slower, for a given photosynthetic output, in trees with dense 233 wood. Relatively more carbon also needs to be allocated to high-density wood, at the 
234 expense of allocation to leaves and fine roots. Although the correlation between WD 235 and more directly instrumental traits for plant hydraulics, such as the Huber value (the 236 ratio of cross-sectional sapwood area to subtended leaf area) (Togashi et al., 2015), 237 vessel density and calibre, and permeability (Reid et al., 2005) is imperfect, these last 238 traits are much more time-consuming to measure than WD and thus comparatively 239 under-represented in available data sets. We anticipate that plants with a lavish water 240 use strategy should present high conductivity and low-density wood, while plants 241 adapted to environments with long droughts, or vulnerable to water use competition, 242 should tend to adopt a conservative water-use strategy and to have high-density wood.

243 The fourth group reflects the ability to compete with other species for light, expressed 244 as potential maximum height $\left(H_{\mathrm{max}}\right)$ : taller plants are able to harvest more light while 245 shorter plants are often more shade-tolerant (Turner, 2001). This group includes $\chi$, 246 which has been reported to show a negative relationship with tree height (Koch et al., 247 2015). The reason $\chi$ belongs with $H_{\max }$ and not with $V_{\mathrm{cmax}}$ in this analysis is because 248 we have intentionally restricted the climatic range to moist forests, so that the 249 variation in $\chi$ is mainly related to plant strategy rather than to aridity or temperature. $250 H_{\max }$ is considered to be a species characteristic and although it may not be reached at 251 every site, its use as an indicator of plant strategy is likely better than using actual 252 observed height, which varies among individuals and over time.

253 Leaf-level measurements were conducted in tropical forests of Queensland, 254 Australia and Yunnan, China, and combined with (a) published and unpublished 255 datasets on $H_{\max }$, WD, and (b) expert knowledge of the species' vegetation dynamical 256 roles (climax, subcanopy, large and small pioneers). Thus we are able to present what 257 is (to our knowledge) the first study to analyse key biochemical rates in the context of 258 tree species' contrasting dynamic roles, and the first empirical trait-based analysis to 259 include measured biochemical rates in a PFT classification with the aim to inform 260 progress in DGVM development. The objective of this work was to quantify trait 261 variation within these forests that can be linked to dynamical roles, but also 262 specifically to test the following predictions: (i) when moisture supply and low 263 temperatures are not limiting factors, photosynthetic capacity should be governed by 264 incident PAR (a prediction of the coordination hypothesis); (ii) $\chi$ should be lower at 265 high $H_{\max }$ (a prediction of the least-cost hypothesis); and (iii) pioneer species should 
266 tend to have low WD, an expectation from the theory of forest dynamics (Shugart, 267 1984).

268 Materials and methods

269 Study Sites

Our analysis includes material from 232 evergreen angiosperm tree species

271 (431 leaf samples) from moist tropical forests of Queensland, northern Australia 272 (Robson Creek on the inland Atherton Tablelands to Cape Tribulation near the Pacific 273 coast) and Yunnan, southwestern China (the Xishuangbanna region in southern 274 Yunnan, near the land borders with Myanmar, Thailand and Laos). Field campaigns 275 conducted in Queensland and Yunnan yielded data on 191 species. Data from these 276 campaigns were combined with data on a further 41 Queensland species from field 277 studies carried out by the TROpical Biomes In Transition (TROBIT) network 278 (Bloomfield et al., 2014). Climates covered by the sampled areas range in mean 279 annual precipitation (MAP) from 1427 to $5143 \mathrm{~mm}$ (Liddell, 2013b, a; Harris et al., 280 2014; Hutchinson, 2014c) and in mean annual temperature (MAT) between 19.0 and $28124.4{ }^{\circ} \mathrm{C}$ (Liddell, 2013b, a; Harris et al., 2014; Hutchinson, 2014a, b). Both 282 Queensland and Yunnan have a marked wet season and 'dry' (drier) season, and 283 although the range of MAP values is considerable, all the sites correspond to climates 284 where moisture is unlikely to be a limiting factor for forest development. The drier 285 season at the Queensland and Yunnan sites lasts four to five months, but there is still typically $100-300 \mathrm{~mm}$ precipitation per month. Gridded climatological data at $0.01^{\circ}$ 287 resolution for 1971-2000 on MAP, MAT, annual Moisture Index (MI, the ratio of 288 precipitation to equilibrium evaporation) and mean monthly photosynthetic active 289 radiation (mPAR) were acquired for the Australian sites at www.tern.org.au. 290 Climatological data for the Chinese sites were derived from records at 1814 291 meteorological stations (740 stations have observations from 1971-2000, the rest from 292 1981-1990: China Meteorological Administration, unpublished data), interpolated to a $2930.01^{\circ}$ grid using a three dimensional thin-plate spline (ANUSPLIN version 4.36, 294 Hancock and Hutchinson, 2006). Fig. 1 and Table 1 provide further details on sites 295 and climates. 


\section{Gas exchange measurements and photosynthetic variables}

We used a portable infrared gas analyser (IRGA) system (LI-6400; Li-Cor, Inc., Lincoln, NB, USA) to perform leaf gas-exchange measurements. Sunlit terminal branches from the top one-third of the canopy were collected and immediately re-cut under water. One of the youngest fully expanded leaves, attached to the branch, was sealed in the leaf chamber. Measurements in the field were taken with relative humidity and chamber block temperature close to those of the ambient air at the time of measurement. The rate of airflow was held constant at $500 \mu \mathrm{mol} \mathrm{s} \mathrm{s}^{-1}$, but exceptionally the flow was reduced (to a minimum of $250 \mu \mathrm{mol} \mathrm{s}{ }^{-1}$ ) under very low stomatal conductance.

We obtained $130 A-c_{i}$ curves from 41 species from Robson Creek (RCRl and $R C R 2)$ in both the dry and the wet season. The $\mathrm{CO}_{2}$ mixing ratios for the $A$ - $c_{i}$ curves proceeded stepwise down from 400 to 35 and up to $2000 \mu \mathrm{mol} \mathrm{mol}^{-1}$. Prior to the measurements, we tested plants to determine appropriate light-saturation levels. The photosynthetic photon flux density (PPFD) adopted for measurement ranged between 1500 and $1800 \mu \mathrm{mol} \mathrm{m} \mathrm{m}^{-2} \mathrm{~s}^{-1}$. After measuring the $A-c_{i}$ curves over about 35 minutes, light was set to zero for five minutes before measuring respiration. This was a timesaving compromise to allow four or five replicate curves per machine per day, based on our experience that stable results are commonly obtained after five minutes. Moreover, this quick estimate should be superior to the common practice of deriving $R_{\text {dark }}$ as one of the parameters in a curve-fitting routine. Following the protocol of Domingues et al. (2010), we discarded 37 of a total $167 A-c_{\mathrm{i}}$ curves in which stomatal conductance $\left(g_{\mathrm{s}}\right)$ declined to very low levels, adversely affecting the calculation of $V_{\text {cmax }}$. These procedures were very similar to the ones applied to the $125 A$ - $c_{\mathrm{i}}$ curves obtained from 26 species in the TROBIT sites (CTR2, KBL1, KBL3 and KCR) during the wet season, further described in Bloomfield et al. (2014).

We sampled 114 leaves of 91 species in Yunnan $(Y 1 X, Y 2 U, Y 3 M 1, Y 3 M 2$, $Y 4 L)$ in the dry season. Data for 62 leaves of 16 species were also obtained from Cape Tribulation in the dry season (CTRl:Weerasinghe et al., 2014). We used the same sampling methods for Yunnan and for Cape Tribulation. PPFD was held constant at $1800 \mu \mathrm{mol} \mathrm{m}^{-2} \mathrm{~s}^{-1}$. For each leaf, we first set the $\mathrm{CO}_{2}$ mixing ratio to $400 \mu \mathrm{mol} \mathrm{mol}^{-1}$ to obtain the rate of photosynthesis under light saturation $\left(A_{\text {sat }}\right)$. Measurement was taken under stable $g_{\mathrm{s}}\left(>0.5 \mu \mathrm{mol} \mathrm{m} \mathrm{m}^{-2} \mathrm{~s}^{-1}\right), \mathrm{CO}_{2}$ and leaf-to-air vapour pressure deficit. 
329 The next step was to increase the $\mathrm{CO}_{2}$ mixing ratio to $2000 \mu \mathrm{mol} \mathrm{mol}^{-1}$ in order to register the rate of photosynthesis under light and $\mathrm{CO}_{2}$ saturation $\left(A_{\max }\right) . R_{\text {dark }}$ was not measured in Yunnan. For $R_{\text {dark }}$ in $C T R 1$, the leaf was wrapped in foil sheets after $A_{\text {sat }}$ and $A_{\max }$ measurements. There was a waiting period of at least 30 minutes of darkness before taking $R_{\text {dark }}$ values.

Values of $V_{\text {cmax }}$ and $J_{\max }$ were fitted using the Farquhar et al. (1980) model.

335 The assumption of unlimited mesophyll conductance (Miyazawa and Kikuzawa, 2006; Lin et al., 2013) remains the standard implementation of the Farquhar model although it is recognized to be an approximation that results in an overestimation of $V_{\text {cmax }}$ and $J_{\max }$. Hence all of the values estimated are 'apparent' $V_{\text {cmax }}$ and $J_{\max }$ values, as in most of the ecophysiological literature. In cases where $A-c_{\mathrm{i}}$ curves were not measured, we estimated $V_{\text {cmax }}$ from $A_{\text {sat }}$ by the so-called one-point method, which inverts the equation for Rubisco-limited photosynthesis taking into account the measured $c_{1}$ and leaf temperature by applying the temperature dependencies of the

343 Michaelis-Menten coefficients of Rubisco for carboxykation $\left(K_{\mathrm{C}}\right)$ and oxygenation $344\left(K_{\mathrm{O}}\right)$ and the photorespiratory compensation point $\left(\Gamma^{*}\right)$ from Bernacchi et al. (2001). 345 The one-point method relies on the assumption that light-saturated photosynthesis 346 measured on field-grown plants is Rubisco-limited, which has been found to be true 347 in almost all cases (De Kauwe et al., 2016). $J_{\max }$ was estimated from $A_{\max }$ on the 348 assumption that high $\mathrm{CO}_{2}$ forces the leaves into electron-transport limitation 349 (Bernacchi et al., 2003). Triose phosphate utilization limitation was not considered, as 350 it would be unlikely to occur at our field temperatures $>22{ }^{\circ} \mathrm{C}$ (Sharkey et al., 2007; 351 Lombardozzi et al., 2018)

\section{Nutrient analyses}

After completion of the leaf gas-exchange measurements, the leaf was retained

354 to determine leaf area, dry mass, and mass-based $N$ and $P$ concentrations $\left(N_{\text {mass }}\right.$ and $355 P_{\text {mass, }} \mathrm{mg}^{-1}$ ). Leaves were sealed in plastic bags containing moist tissue paper to 356 prevent wilting. Leaf area was determined using a $600 \mathrm{dot} / \mathrm{inch}$ flatbed top357 illuminated optical scanner and Image $\mathbf{J}$ software (http://imagej.nih.gov/ij/). Leaves 358 were dried in a portable desiccator for 48 hours for preservation until the end of the 359 campaign and subsequently oven-dried in the laboratory for 24 hours at $70^{\circ} \mathrm{C}$. Then 360 the dry weight was determined (Mettler-Toledo Ltd, Port Melbourne, Victoria, 
361 Australia). LMA $\left(\mathrm{g} \mathrm{m}^{-2}\right)$ was calculated from leaf area and dry mass. $N_{\text {mass }}$ and $P_{\text {mass }}$ 362 were obtained by Kjeldahl acid digestion of the same leaves (Allen et al., 1974). The 363 leaf material was digested using 98\% sulphuric acid and 30\% hydrogen peroxide. 364 Digested material was analyzed for $N$ and $P$ using a flow injection analyser system 365 (LaChat QuikChem 8500 Series 2, Lachat Instruments, Milwaukee, WI, USA). $N_{\text {area }}$ 366 and $P_{\text {area }}\left(\mathrm{mg} \mathrm{m}^{-2}\right)$ were calculated as products of LMA and $N_{\text {mass }}$ or $P_{\text {mass. }}$ TROBIT 367 nutrient analysis was performed using similar methods but different equipment, as 368 described in Bloomfield et al. (2014).

\section{Wood density and tree height}

Twenty-year series of wood density $(W D)$, tree height $(H)$, and tree diameter at breast height $(D)$ were obtained from Bradford et al. (2014a) $(n=138)$. Maximum tree height $\left(H_{\max }\right)$ was estimated using the derivative of the Mitscherlich function relating diameter and height (Li et al., 2014):

$$
\mathrm{d} H / \mathrm{d} D=a \exp \left(-a D / H_{\max }\right)=a\left(1-H / H_{\max }\right)
$$

where $a$ is the initial slope of the relationship between height and diameter. A typical range of $a$ in the literature is $116 \pm 4.35$.

\section{Dynamic roles of species}

Australian species $(n=61)$ were assigned to dynamic roles with the help of 379 the database published by Bradford et al. (2014b) and expert knowledge by MB. 380 Chinese species $(n=85)$ were assigned to dynamic roles based on expert knowledge 381 by ZH. These 'expert' classifications (A1) were compared with a quantitative trait382 based classification (A2) as described in the next section. Both classification 383 approaches were implemented according to the Shugart (1984) framework, which can also be related to those of Denslow (1987), Turner (2001) and Fyllas et al. (2012):

(1) Requires a gap, and produces a gap. These are long-lived pioneers that reach the canopy. Shade intolerant.

388 (2) Does not require a gap, but produces a gap. These are long-lived climax species that reach the canopy and grow large. Shade tolerant. 
390 (3) Requires a gap, but does not produce a gap. These are short-lived pioneers that never grow large. Shade intolerant.

392 (4) Does not require a gap, and does not produce a gap. These are sub-canopy species.

393 Shade tolerant.

The geographic distribution of expert assessment of dynamic roles per number of species and per number of leaves is shown in Table 2. This dataset includes 262 observations.

\section{Statistical analyses}

All statistics were performed in R (R Core Team, 2012). For graphing we used the ggplot2 package (Wickham, 2010). Moisture index was represented in Fig. 1 as its square root, a transformation appropriate to precipitation values (M.F. Hutchinson, personal communication, 2011), which approximately normalizes the distribution of

403 values and thus contains the large spread of values at the high end. $V_{\mathrm{cmax}}, J_{\max }, R_{\mathrm{dark}}$, 404 LMA, $N_{\text {area }}, P_{\text {area }}, H_{\max }$ and WD data were $\log _{10}$-transformed, unless otherwise 405 indicated, achieving an approximately normal distribution of values. $\chi$ was logittransformed as this variable is bounded between 0 and 1, and the logit transformation results in approximately linear relationships between the transformed ratio and environmental predictors, including temperature (Wang et al., 2017). Ordinary leastsquares linear regression was used to test relationships between plant traits and climate variables. Pairwise combinations of quantitative traits were tested for

411 significant relationships across all data, and within groups corresponding to high and 412 low MI, high and low mPAR, and high and low MAT. Slopes and elevations of 413 regressions were compared using standardized major axis regression with the smatr 414 package (Warton et al., 2006). The package vegan (Oksanen et al., 2015) was used 415 to assess multivariate trait variation, using the following methods:

- Principal component analysis (PCA) of nine plant traits $\left(V_{\mathrm{cmax}}, J_{\mathrm{max}}, R_{\mathrm{dark}}\right.$, LMA, $N_{\text {area }}, P_{\text {area }}, H_{\max }$, WD and $\left.\chi\right)$;

- Redundancy analysis (RDA) of the same nine traits, constrained by three climate variables (MI, mPAR and MAT);

- RDA of the same nine traits, constrained by dynamic roles (as factors); and 
- RDA of the same nine traits constrained simultaneously by both climate and dynamic roles.

423 PCA was used to identify patterns of covariation among traits irrespective of their 424 dynamic or environmental correlates, and RDA to analyse multivariate trait 425 relationships to predictors. Note that PCA is an exploratory method with no 426 associated formal test of significance. By contrast, the significance of trait427 environment relationships identified by RDA can be assessed approximately in a 428 similar way to generalized linear models (Ter Braak and Prentice, 1988). The $K$ 429 means (R Core Team, 2012) clustering method was used to create four groups of 430 species based on the nine plant traits (A2: Dynamic roles based on quantitative 431 assessment). $K$-means clustering was performed with the number of iterations set to 432100 and bootstrapped with 10,000 repetitions. RDA and bivariate correlations were 433 used to compare classifications A2 and A1. The dataset used for PCA and RDA 434 analysis consisted of 130 observations with information for all traits, climate variables 435 and dynamic roles. All RDA visualizations here follow the response-variable focused 436 'Type 2 scaling' (Oksanen et al., 2015), such that the angles between pairs of vectors 437 as plotted approximate their pairwise correlations. For PCA and RDA input data 438 where direct measurements of $R_{\text {dark }}$ were not available, $R_{\text {dark }}(\mathrm{n}=58)$ was estimated 439 from $A_{\text {sat }}$ following Prentice et al. (2014) using the approximation $R_{\text {dark }} \approx 0.01 V_{\text {cmax }}$ 440 (De Kauwe et al., 2016).

\section{$441 \quad$ Research data}

Robson Creek (RCRl and $R C R 2)$ data can be requested at www.tern.org.au 443 (Prentice et al., 2013). Access to TROBIT data (CTR2, KBL1, KBL3 and KCR) and 444 Cape Tribulation 1 (CTRl) are described in Bloomfield et al. (2014) and Weerasinghe 445 et al. (2014) respectively. For Yunnan data $(Y 1 X, Y 2 U, Y 3 M 1, Y 3 M 2, Y 4 L)$, refer to 446 Wang et al. (2018).

\section{$448 \quad$ Results}

\section{Trait values and dimensions of variation}

Average values of the metabolic traits $V_{\mathrm{cmax}}, J_{\max }$, and $R_{\text {dark }}$ were 52.0, 82.0, 451 and $0.63 \mu \mathrm{mol} \mathrm{m} \mathrm{m}^{-2} \mathrm{~s}^{-1}$ respectively. The corresponding ranges were 4.2 to $148.9,14.0$ 
452 to 203.6, and near zero to $3.70 \mu \mathrm{mol} \mathrm{m} \mathrm{m}^{-2} \mathrm{~s}^{-1}$. Average values of the 453 chemical/structural traits LMA, $N_{\text {area }}$ and $P_{\text {area }}$ were $110.9 \times 10^{3}, 0.19 \times 10^{3}$ and 0.013 $454 \mathrm{~g} \mathrm{~m}^{-2}$ with ranges of 12.04 to $610.3 \times 10^{3}$ (LMA), near zero to $1.49 \mathrm{~g} \mathrm{~m}^{-2}$ ( $\left.N_{\text {area}}\right)$, and near zero to $0.06 \mathrm{mg} \mathrm{m}^{-2}\left(P_{\text {area }}\right)$. Average values of $\chi, H_{\max }$ and WD were $0.71,26.3 \mathrm{~m}$ and $0.55 \mathrm{~g} \mathrm{~cm}^{-3}$ with ranges of 0.39 to $0.94,1.3$ to $54.5 \mathrm{~m}$, and 0.33 to $0.98 \mathrm{~g} \mathrm{~cm}^{-3}$ respectively.

Four orthogonal dimensions of trait variation were identified corresponding to the metabolic, chemical/structural, hydraulic and height trait groups described above 460 (Fig. 2, Table 3). The metabolic traits $V_{\mathrm{cmax}}, J_{\max }$ and $R_{\text {dark }}$ varied continuously and in 461 close correlation with one another. $V_{\mathrm{cmax}}$ and $\chi$ were negatively correlated, but the correlation was weak (not shown: slope $=-1.85$, intercept $=1.32, \mathrm{R}^{2}=0.13, p<$ 0.05). Table 3 makes it clear that variation in $\chi$ in this data set does not belong to the metabolic dimension. The chemical/structural traits LMA, $N_{\text {area }}$ and $P_{\text {area }}$ were positively correlated with one another $(p<0.05)$, although the pairwise relationship of $466 P_{\text {area }}$ to LMA was weaker than that of $N_{\text {area }}$ to LMA. The strong correlation between $467 \quad$ LMA and $N_{\text {area }}$ suggests that much of the $\mathrm{N}$ content in the leaves is structural rather than metabolic (see also Yang et al., 2018). A similar result was obtained when massrather than area-based nutrient values were used in the PCA (not shown). The third dimension was mostly represented by variation in WD, with some contribution from $P_{\text {area. }}$. Finally $H_{\max }$ and $\chi$ had a non-significant negative pairwise relationship and were associated with the fourth dimension, suggesting a trade-off between water loss and the length of the water-transport pathway. These dimensions of trait variation are broadly in agreement with those described by Baraloto et al. (2010), Fyllas et al. (2012) and Reich (2014).

\section{Contribution of climate variables to trait variation}

High and low values for MI, mPAR and MAT were defined as values above or below the mean value of the climate variable. Regression slopes between $V_{\text {cmax }}$ and $J_{\max }$ for both high MI and low MI groups were close together but statistically distinct $(p<0.05$, Fig. 3), and the same was true for high versus low mPAR and MAT groups (Fig. 3). Regressions for $V_{\mathrm{cmax}}$ versus $N_{\text {area }}$ were not significant within these climatic groups (Fig. 3) but the relationship was significant, albeit weak, when all of the data were considered together (not shown: slope $=0.69, \mathrm{R}^{2}=0.10, p<0.05$ ). The 
weakness of this relationship corroborates our previous assessment of leaf $\mathrm{N}$ content as being primarily structural rather than metabolic. High MI and low mPAR were associated with high $V_{\mathrm{cmax}}, J_{\max }$, and $N_{\text {area }}$ (Fig. 3). These variables were also associated with $R_{\text {dark }}$ and LMA. The remaining traits $\chi, P_{\text {area }}, H_{\max }$ and WD were very scattered against MI and mPAR (no significant relationship). All traits had high and low values spanning the full range of MAT.

The clustered vectors for metabolic traits, MI and MAT in Fig. 4 indicate that higher moisture and air temperature favour species with higher metabolic rates (Fig. 4). The RDA constrained by climate variables explained $35 \%$ of trait variation with $19 \%$ and $11 \%$ on axes 1 and 2 respectively ( $p<0.05$, Fig. 4). This represents an unexpectedly large fraction of the trait variation, considering the modest range in MAT (19 to $24^{\circ} \mathrm{C}$ ), mPAR (27.4 to $30.5 \mathrm{~mol} \mathrm{~m}^{-2}$ ) and MI (0.9 to 2.5; i.e. typical values for non-drought-stressed conditions) among these tropical moist forest sites. No individually significant trait-climate variable relationship was found. An association of high metabolic rates with aridity (Prentice et al., 2011) has been found when considering longer climate gradients, but this is not apparent over the more limited climatic range sampled here.

\section{Contribution of dynamic roles to trait variation}

The assignment of the four groups obtained by $K$-means clustering to dynamic roles was based on the degree of correspondence between the mean values of plant traits for each group and the classification by Shugart (1984). $H_{\max }$ determined whether a cluster was labeled as climax or large pioneer, or small pioneer or subcanopy. Higher values of photosynthetic traits defined tall trees as climax, as opposed to large pioneer, and small trees as small pioneer, as opposed to subcanopy.

Expert (A1) and quantitative (A2) role definitions explained $23 \%$ and $55 \%$ of total plant trait variance, respectively (Fig. 5). With respect to patterns, the RDA results obtained with the two classifications are quite similar to one another, which is expected as the clustering was performed using the same trait data represented in the RDA. However, the quantitative role definitions explained substantially more variance than the expert definitions. The major common patterns shown in the two RDA plots are as follows: 
516 (1) The metabolic traits $V_{\mathrm{cmax}}, J_{\max }, R_{\text {dark }}$ and the structural-chemical traits $N_{\text {area }}$ and

517 LMA tend to be higher in climax species than in the other groups.

518 (2) $P_{\text {area }}$ tends to be greater in subcanopy species than in the other groups.

519 (3) WD tends to be smaller in pioneer species than in the other groups.

521 These distinctions are supported, and further information provided, by the summary

522 statistics for trait variation within each group (Fig. 6). Climax species consistently

523 have the highest values of $V_{\mathrm{cmax}}, J_{\max }, R_{\text {dark }}$, LMA and $N_{\text {area. }}$ High WD, consistent with

524 slow growth, characterized the subcanopy species. The $\chi$ ratio was lowest in climax

525 species and highest in subcanopy species. The scaling slopes of the bivariate

526 relationships between $V_{\mathrm{cmax}}$ and $J_{\max }$, and between $V_{c m a x}$ and $N_{\text {area }}$, were largely similar

527 within each group, whether the roles were defined quantitatively or by expert

528 assessment (Fig. 7).

\section{Partitioning trait variance to climate variables versus dynamic roles}

RDA constrained by the two sets of predictors (climate and dynamic roles)

531 both separately and collectively provides the necessary information to partition the

532 total explained variation into the unique contributions of each set and a combined 533 contribution associated with covariation of the two sets, via the Legendre variation 534 partitioning method (Legendre and Anderson, 1999; Peres-Neto et al., 2006; Meng et 535 al., 2015; Yang et al., 2018). Based on the quantitative assessment of dynamic roles

536 (A2), RDA constrained by both sets of predictors explained $61 \%$ of trait variation, 537 which could be partitioned as follows: $26 \%$ from dynamic roles alone, $6 \%$ from 538 climate alone, and 29\% from the combination. The corresponding figures based on 539 expert assessment were as follows: $43 \%$ of trait variation explained, composed of $8 \%$ 540 from dynamic roles alone, $20 \%$ from climate alone, and $15 \%$ from the combination.

541 Although significant trait variation was linked to climate, individual trait542 climate relationships were weak and patterns that have been observed across a wider 543 range of climates, such as the widely reported increase of $N_{\text {area }}$ with aridity, were not 544 present. This pattern is to be expected considering that semi-arid and arid ecosystems 545 are not considered. Variance partitioning showed that between 8 and $26 \%$ of trait 546 variation (depending on the source of information on dynamics roles) could not be 
attributed to the temperature and moisture regime, but could be related uniquely to species' dynamic roles.

\section{Unexplained trait variance}

Unexplained variance amounted to $57 \%$ and $39 \%$ for the expert and quantitative assessments, respectively. In principle unexplained variance might be related to a variety of factors including the season of measurement, forest age and aspects of soil fertility. However, dividing the data according to wet-season (CTR2, $K B L 1, K B L 3, K C R, R C R s)$ versus dry-season (CTR1, RCRw, Y1X, Y2U, Y3M1, Y3M2, $Y 4 L)$ measurements yielded patterns similar to those found in the full data set. No data on forest age were available. No correlations were found between trait values and soil total $\mathrm{N}$, soil total $\mathrm{P}$ and cation exchange capacity (Table 1).

\section{Discussion}

This study provides support for the idea that forest dynamic roles, as described by Shugart (1984), might be systematically related to the biophysical and ecophysiological traits used in DGVMs. Our analysis explores plant trait diversity and plasticity with a view to more realistic modelling of plant and vegetation processes,

564 whether for local or global model applications (Fyllas et al., 2009; 2012; Quesada et

565 al., 2012). Expert classification of dynamic roles in forests is notoriously difficult because it requires observation over many decades. Our quantitative analyses suggest a possible alternative approach to classification based on trait measurements at one point in time. Moreover, our results have supported certain specific predictions of the

569 least-cost and coordination hypotheses, which are key to explaining species strategies, 570 community assembly and ecosystem structure and function (Reich, 2014). They

571 collectively hold the promise of providing general, testable trait-environment 572 relationships that could reduce the excessive number of parameters required by most 573 DGVMs (Prentice et al., 2015).

\section{Dynamic roles and the coordination hypothesis}

575 Our results support a core prediction of the coordination hypothesis for forests: that $J_{\max }$ and $V_{\text {cmax }}$ should be higher under high illumination and lower in the 
shade, as seen both in the vertical gradient of light-saturated assimilation rates in dense canopies (Chen et al., 1993) and more generally, in the solar radiation gradient across canopies situated in diverse environments (Maire et al., 2012). With respect to dynamic roles, outer-canopy climax species are expected to receive most PAR and therefore should have the highest photosynthetic capacity, while subcanopy species should have the lowest. Pioneer (gap-requiring) species would be expected to have intermediate photosynthetic capacity and this too is consistent with our findings. Additionally, the widely reported conservative ratio of $J_{\max }$ and $V_{\mathrm{cmax}}$ seems to be maintained, both within and across dynamic roles. The association of $R_{\text {dark }}$ with $V_{\text {cmax }}$ and $J_{\max }$ was also found to be strong, with $R_{\text {dark }}$ maintaining a near constant ratio for leaves whether in sun-exposed or shade conditions, as previously reported (e.g. by Hirose and Werger, 1987; Weerasinghe et al., 2014; Atkin et al., 2015).

The observed relationships among $N_{\text {area, }} P_{\text {area }}$ and LMA, and the weaker correlations of these traits with primary metabolic traits, reflect the fact that a

591 substantial part of the $\mathrm{N}$ and $\mathrm{P}$ content of leaves is not directly tied to photosynthetic functions (Dong et al., 2017). Although strong linear relationships between $V_{\text {cmax }}$ (at a reference temperature) and $N_{\text {area }}$ seem to be widely expected, they are not always

594 found (Prentice et al., 2014; Togashi et al., 2017), perhaps due to the overpowering 595 effect of variation in structural and/or defensive components of leaf $\mathrm{N}$. The 596 photosynthetic component of $N_{\text {area }}$ however is expected to be proportional to incident 597 PAR. This expectation is supported by the analysis of Dong et al. (2017), and by our 598 finding of highest $N_{\text {area }}$ among climax species.

\section{Dynamic roles and the least-cost hypothesis}

It has been reported that $\chi$ declines with tree height. This too is a prediction of 601 the least-cost hypothesis (Prentice et al., 2014), as the cost of maintaining the water 602 transport pathway increases at with height. Therefore, tall trees - and the top stratum 603 of leaves in a tall tree, as noted by Koch et al. (2015) - may be expected to aim for a 604 lower optimum $\chi$ by investing more in the maintenance of biochemical capacity and 605 less in the maintenance of transport capacity. Even if the path-length effect on stem 606 hydraulic conductance is fully compensated by xylem tapering (Tyree and Ewers, 607 1991; Enquist and Bentley, 2012; Olson et al., 2014) as often seems to be the case, it 608 is still more expensive in terms of sapwood respiration to maintain a tall stem as 
opposed to a short stem (Prentice et al., 2014). This prediction is supported by the low $\chi$ found here in climax species. However, surprisingly, large pioneer species (with

$611 H_{\max }$ equivalent to climax species) did not show this adaptation. Subcanopy species

612 did nonetheless show high $\chi$, consistent with their short stature. Given a reduced $\chi$, the

613 coordination hypothesis then predicts that $V_{\mathrm{cmax}}$ should be increased. This mechanism 614 may additionally contribute to the high $V_{\mathrm{cmax}}$ found in climax species and the low $615 V_{\text {cmax }}$ in subcanopy species.

616 Dynamic roles, the leaf economics spectrum and the theory of forest dynamics

617 A third group of predictions broadly supported by our results comes from the 618 framework presented in Shugart (1984), Turner (2001) and Fyllas et al. (2012). This 619 approach considers two main axes of ecological specialization, one reflecting canopy 620 position and access to light, the other life span and growth rate. The main advantage 621 for large pioneers in rapidly achieving tall stature is to shade lower canopies nearby, 622 while obtaining rapid access to full sunlight. Compared to climax species, large 623 pioneers adopt a less conservative strategy regarding water use, and are likely to have 624 a shorter lifespan (Shugart, 1984; Reich, 2014). One way to achieve fast growth is to 625 invest in low-density conducting tissues, which implies lower WD. Subcanopy 626 species by contrast are necessarily shade-tolerant and often have traits associated with 627 slow growth. Our results support the existence of this tradeoff, with subcanopy trees 628 having generally high WD (a trait often accompanied by a high density of short and 629 narrow vessels: Reich, 2014).

630 According to the LES, across species globally, high LMA is linked to 631 longevity of individual leaves; and it has generally been found that LMA varies as 632 much or more within communities as with environmental gradients (Wright et al., 633 2004). Our data do not allow us to address the LMA-lifespan linkage directly. 634 However, they do show that LMA varies systematically across the dynamic roles, 635 being greatest in climax species and associated with high $V_{\mathrm{cmax}}$ and least in subcanopy 636 species where it is associated with low $V_{\text {cmax. }}$. These findings suggest a more nuanced 637 interpretation of the variation in LMA among dynamic roles. Namely: that thick, 638 high-LMA leaves are a pre-requisite for a leaf to attain $V_{\mathrm{cmax}}$ commensurate with high 639 levels of PAR at the top of a canopy (Niinemets and Tenhunen, 1997), while thin, 640 low-LMA leaves provide optimum light capture for the least investment in leaves - a 
641 good strategy for subcanopy species. Fast-growing pioneer species with their high 642 water-use strategy also require a low investment in leaf structure, developing thin, 643 low-LMA leaves in order to obtain a quicker return on investment (Turner, 2001).

644 The downside is that these leaves are likely to be more exposed to herbivory losses, 645 while the low-density stems are subject to the risks of cavitation and embolism, 646 shortening their life expectancy (Enquist and Bentley, 2012).

\section{Implications for modelling}

DGVMs based on continuous trait variation have been developed in response to the growing realization that PFTs, as conventionally defined, do not adequately describe the genotypic or phenotypic plasticity of plant traits in the real world. The

651 existence of systematic, adaptive trait variation in forests, within a climate range 652 where neither moisture nor low temperature is limiting, provides further support for 653 the conclusion (e.g. Meng et al., 2015) that models should not be based on fixed, 654 PFT-specific values for many quantitative traits. In general, consideration of the 655 adaptive function of trait differences among dynamic roles should contribute to 656 reducing the multiplicity of uncertain parameters, and simultaneously increase the 657 realism, of next-generation DGVMs. DGVMs in general (including recent trait-based 658 vegetation models, with the exception of the model of Fyllas et al., 2014 developed 659 for Amazonian forests) have paid minimal attention to the co-existing functional 660 diversity of traits present in communities where climate variation is small but tree 661 species diversity is large, including tropical forests. Our results suggest that the 662 framework provided by optimality concepts (the coordination and least-cost 663 hypotheses) could be combined with classical forest dynamics theory, which 664 differentiates complementary survival strategies for tree species in a highly 665 competitive environment, to yield successful predictions that would allow vegetation 666 dynamics to be represented more faithfully in DGVMs. The combination of these 667 different research strands can be achieved by extending existing predictions about 668 trait-environment relationships based on optimality considerations to cover biotically 669 induced microhabitat variation within complex plant communities.

We therefore suggest that the ecophysiological correlates of species dynamical 671 roles be further analysed in other tropical and extratropical forests, as part of the 672 empirical research required to establish a firmer foundation for next-generation 
673 vegetation models. Moreover, we look forward to the widespread use of adaptive 674 schemes in which trait combinations, such as those characterizing species' dynamical 675 roles, emerge naturally from the competition among plants.

\section{Acknowledgments}

This research was funded by the Terrestrial Ecosystem Research Network 679 (TERN, www.tern.org.au), which has been supported by the Australian Government 680 through the National Collaborative Research Infrastructure Strategy (NCRIS), with 681 additional funding provided by Macquarie University and the Australian National 682 University. HFT and ND were supported by Macquarie University International 683 Research Scholarship (iMQRES) awards to ICP. ICP, BJE, HFT and ND have been 684 supported by the Ecosystem Modelling and Scaling Infrastructure Facility (eMAST, 685 http://www.emast.org.au). Data were collected in North Queensland at field sites of 686 the Australian SuperSite Network. Both eMAST and the Australian SuperSites 687 Network are facilities of TERN. OA acknowledges the support of the Australian 688 Research Council (DP130101252 and CE140100008). Leaf N and P mesaurements 689 were made at the Department of Forestry, ANU. We are grateful to Jinlong Zhang 690 (Xishuangbanna Tropical Botanical Garden) for identifying plant species, and also to 691 Jack Egerton (ANU), Li Guangqi (Macquarie), Lingling Zhu (ANU), Danielle Creek 692 (University of Western Sydney), Lucy Hayes (ANU) and Stephanie McCaffery 693 (ANU) for help with fieldwork and/or N and P digestions. We thank Tomas Ferreira 694 Domingues (University of São Paulo) for comments that helped to improve this paper. 695 ND and SPH acknowledge support from the ERC-funded project GC2.0 (Global 696 Change 2.0: Unlocking the past for a clearer future, grant number 694481). This 697 research is a contribution to the AXA Chair Program in Biosphere and Climate 698 Impacts and the Imperial College initiative on Grand Challenges in Ecosystems and 699 the Environment (ICP). 
701 Table 1. Climate averages $(\mathrm{MAT}=$ mean annual temperature, $\mathrm{MI}=$ Moisture Index,

702 mPAR = mean monthly photosynthetic active radiation), geographic location,

703 elevation above sea level and soil properties (CEC $=$ cation exchange capacity, $\mathrm{TN}=$

704 total soil nitrogen, $\mathrm{TP}=$ total soil phosphorus) of the study sites in north-east

705 Australia (CTR1, CTR2, KBL1, KBL3, KCR, RCRs, RCRw) and south-east China

$706(Y 1 X, Y 2 U, Y 3 M 1, Y 3 M 2, Y 4 L)$.

\begin{tabular}{|c|c|c|c|c|c|c|c|c|c|c|}
\hline SITE & LON & LAT & $\begin{array}{l}\text { Altitude } \\
\text { (m) }\end{array}$ & $\begin{array}{l}\text { MAT } \\
\left({ }^{\circ} \mathrm{C}\right)\end{array}$ & $\begin{array}{l}\text { MAP } \\
(\mathrm{mm})\end{array}$ & $\begin{array}{l}\mathrm{mPAR} \\
\left(\mathrm{mol} / \mathrm{m}^{2}\right)\end{array}$ & MI & $\mathrm{CEC}(\mathrm{cmol} / \mathrm{kg})$ & $\begin{array}{l}\text { TN } \\
(\%)\end{array}$ & TP (\%) \\
\hline CTR1 & 145.45 & -16.10 & 64 & 24.4 & 5143 & 27.5 & 2.54 & 11.8 & 0.64 & 0.023 \\
\hline CTR2 & 145.45 & -16.10 & 90 & 24.4 & 5143 & 27.5 & 2.54 & 11.8 & 0.02 & 0.011 \\
\hline KBL1 & 145.54 & -17.76 & 761 & 20.4 & 1976 & 28.2 & 1.39 & 10.83 & 0.08 & 0.030 \\
\hline KBL3 & 145.54 & -17.69 & 1055 & 19.0 & 1726 & 28.3 & 1.22 & 11.11 & 0.08 & 0.030 \\
\hline KCR & 145.60 & -17.11 & 813 & 19.6 & 2541 & 27.9 & 1.82 & 9.81 & 0.01 & 0.006 \\
\hline RCRs & 145.63 & -17.12 & 700 & 19.4 & 2246 & 27.9 & 1.29 & 4.3 & 0.18 & 0.019 \\
\hline RCRw & 145.63 & -17.12 & 700 & 19.4 & 2246 & 27.9 & 1.29 & 4.3 & 0.18 & 0.019 \\
\hline Y1X & 101.27 & 21.92 & 502 & 21.7 & 1427 & 30.1 & 0.94 & 8.68 & 0.08 & 0.044 \\
\hline $\mathrm{Y} 2 \mathrm{U}$ & 101.24 & 21.98 & 1075 & 19.7 & 1562 & 30.6 & 1.03 & 6.09 & 0.08 & 0.044 \\
\hline Y3M1 & 101.58 & 21.61 & 668 & 19.6 & 1662 & 29.8 & 1.14 & 10.21 & 0.08 & 0.050 \\
\hline Y3M2 & 101.58 & 21.62 & 828 & 20.5 & 1604 & 29.9 & 1.07 & 10.21 & 0.08 & 0.050 \\
\hline Y4L & 101.58 & 21.62 & 1034 & 20.5 & 1604 & 30.1 & 1.06 & 10.21 & 0.08 & 0.050 \\
\hline
\end{tabular}

708 Table 2. Geographic distribution of expert assessment of dynamic roles per number of 709 species and per number of leaves for the study sites in north-east Australia (CTR1, $710 C T R 2, K B L 1, K B L 3, K C R, R C R s, R C R w)$ and south-east China $(Y 1 X, Y 2 U, Y 3 M 1$, $711 Y 3 M 2, Y 4 L)$. This dataset includes 262 observations.

\begin{tabular}{lcccc} 
& \multicolumn{4}{c}{ Number of species } \\
\cline { 2 - 5 } & climax & $\begin{array}{c}\text { large } \\
\text { pioneer }\end{array}$ & $\begin{array}{c}\text { Small } \\
\text { pioneer }\end{array}$ & subcanopy \\
\hline CTR1 & 7 & 4 & & 1 \\
CTR2 & 4 & 1 & & \\
KBL1 & 2 & 4 & & \\
KBL3 & 3 & 4 & & \\
KCR & 3 & 5 & & \\
RCRs & 7 & 16 & 3 & 4 \\
RCRw & & 8 & 1 & \\
Y1X & & 2 & & \\
Y2U & & 3 & & 1 \\
Y3M1 & & & & 1 \\
Y3M2 & & & & 1 \\
Y4L & & & &
\end{tabular}

\begin{tabular}{|c|c|c|c|}
\hline \multicolumn{4}{|c|}{ Number of leaves } \\
\hline climax & $\begin{array}{l}\text { large } \\
\text { pioneer }\end{array}$ & $\begin{array}{l}\text { Small } \\
\text { pioneer }\end{array}$ & subcanopy \\
\hline 27 & 16 & & 4 \\
\hline 11 & 5 & & \\
\hline 7 & 25 & & \\
\hline 17 & 13 & & \\
\hline 9 & 17 & & \\
\hline 9 & 52 & 7 & 4 \\
\hline & 26 & 4 & \\
\hline & 2 & & \\
\hline & 3 & & 1 \\
\hline & & & 2 \\
\hline & & & 1 \\
\hline
\end{tabular}


713 Table 3. Principal Component Analysis loadings for nine traits. The highest 714 correlations (absolute magnitudes $>0.45$ ) are indicated in bold.

\begin{tabular}{lrrrr}
\hline & PC1 & PC2 & PC3 & PC4 \\
\hline $\log \mathrm{V}_{\text {cmax }}$ & $\mathbf{- 0 . 4 8}$ & -0.27 & 0.21 & 0 \\
$\log \mathrm{J}_{\max }$ & $-\mathbf{0 . 4 6}$ & -0.25 & 0.18 & 0.04 \\
$\log \mathrm{R}_{\text {dark }}$ & $-\mathbf{0 . 4 5}$ & -0.16 & 0.27 & -0.01 \\
$\log \mathrm{LMA}$ & -0.32 & $\mathbf{0 . 5 5}$ & -0.21 & 0.03 \\
$\log \mathrm{N}_{\text {area }}$ & -0.37 & $\mathbf{0 . 4 5}$ & -0.24 & -0.12 \\
$\log \mathrm{P}_{\text {area }}$ & -0.08 & $\mathbf{0 . 5 4}$ & $\mathbf{0 . 4 5}$ & 0.03 \\
$\log$ WD & 0.15 & 0.1 & $\mathbf{0 . 6 8}$ & -0.16 \\
$\log \mathrm{H}_{\max }$ & -0.2 & -0.15 & -0.24 & $-\mathbf{0 . 7 4}$ \\
$\operatorname{logit} \chi$ & 0.23 & 0.11 & 0.16 & $-\mathbf{0 . 6 4}$ \\
\hline & $\mathrm{PC1}$ & $\mathrm{PC2}$ & $\mathrm{PC3}$ & $\mathrm{PC4}$ \\
\hline $\begin{array}{l}\text { Standard } \\
\text { deviation }\end{array}$ & 1.84 & 1.26 & 1.09 & 0.98 \\
$\begin{array}{l}\text { Proportion } \\
\text { of Variance }\end{array}$ & 0.37 & 0.18 & 0.13 & 0.11 \\
Cumulative & & & & \\
Proportion & 0.37 & 0.55 & 0.68 & 0.79 \\
\hline
\end{tabular}




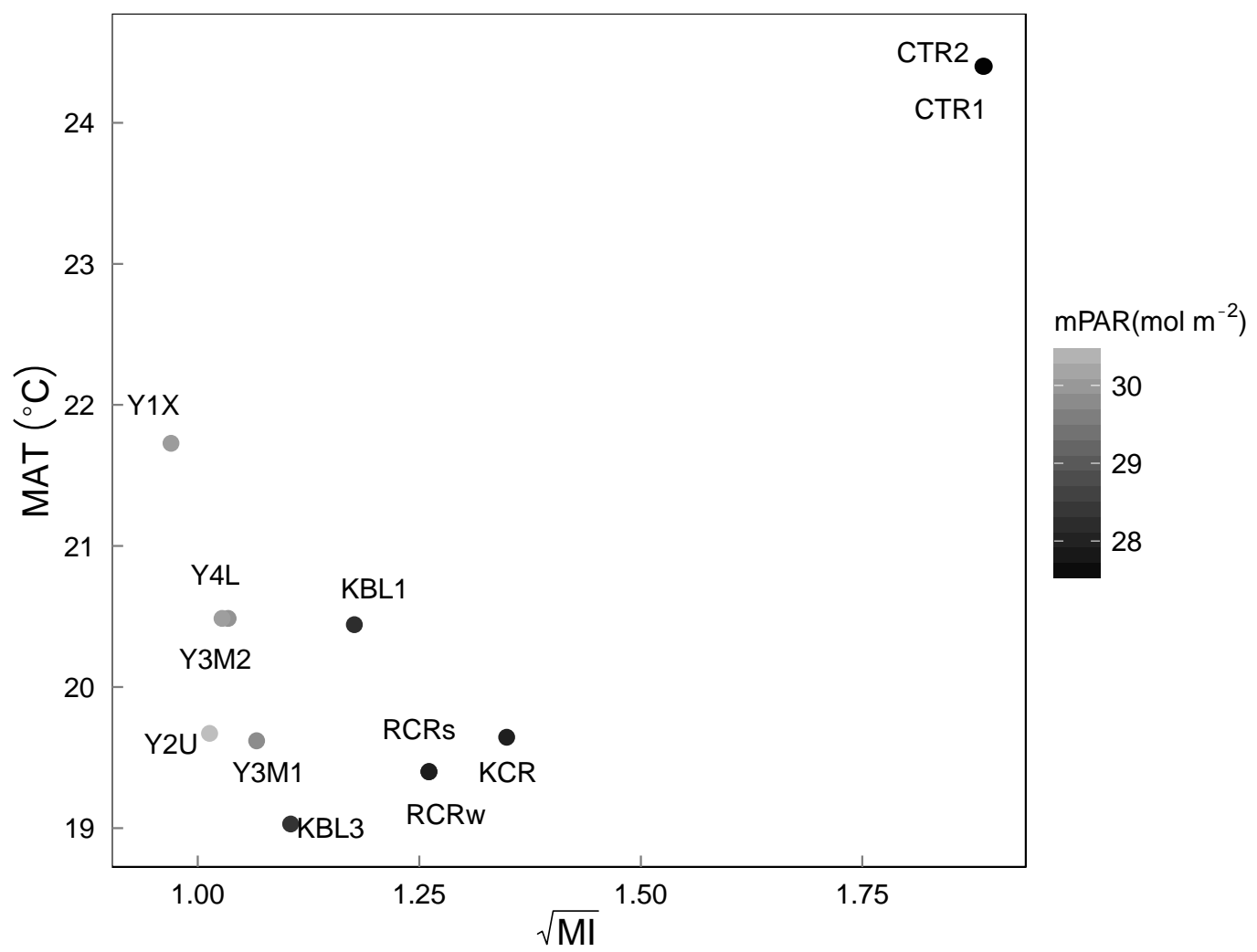

717

718 Fig. 1. Mean annual temperature (MAT, $\left.{ }^{\circ} \mathrm{C}\right)$, the square root of Moisture Index (MI,

719 ratio of precipitation to equilibrium evapotranspiration) and mean monthly 720 photosynthetic active radiation $\left(\mathrm{mPAR}, \mathrm{mol} \mathrm{m} \mathrm{m}^{-2}\right.$ ) for northern Australia (CTRl, 721 CTR2, KBL1, KBL3, KCR, RCRs, RCRw) and southwestern China (Y1X, Y2U, Y3M1, $722 Y 3 M 2, Y 4 L)$. 


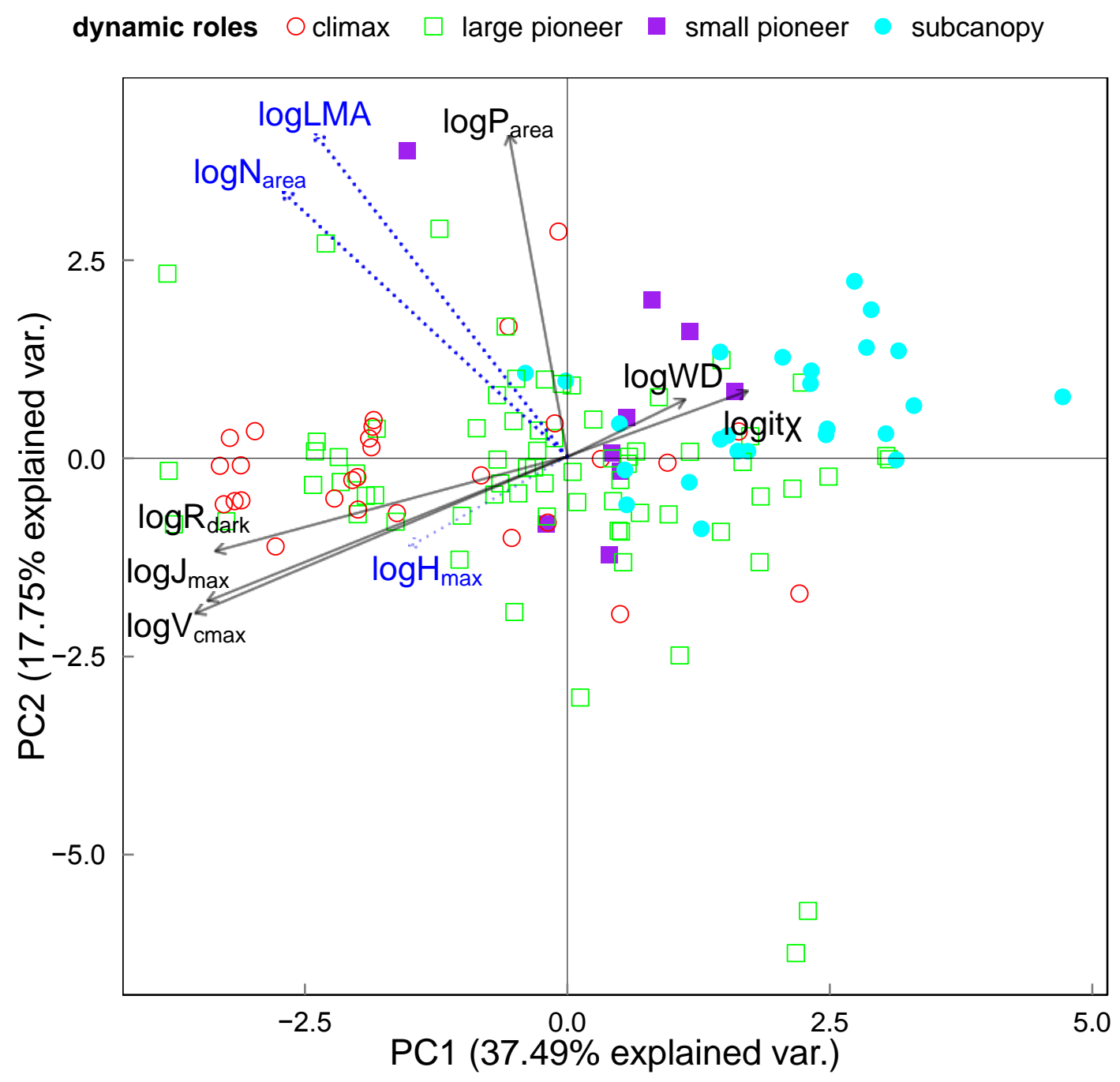

Fig. 2. Principal component analysis (PCA) of nine traits in northern Australia and

725 southwestern China $(n=130)$. Blue dotted lines and names extend backwards from

726 the plane of the paper; and black lines and names protrude forwards towards the 727 observer. 

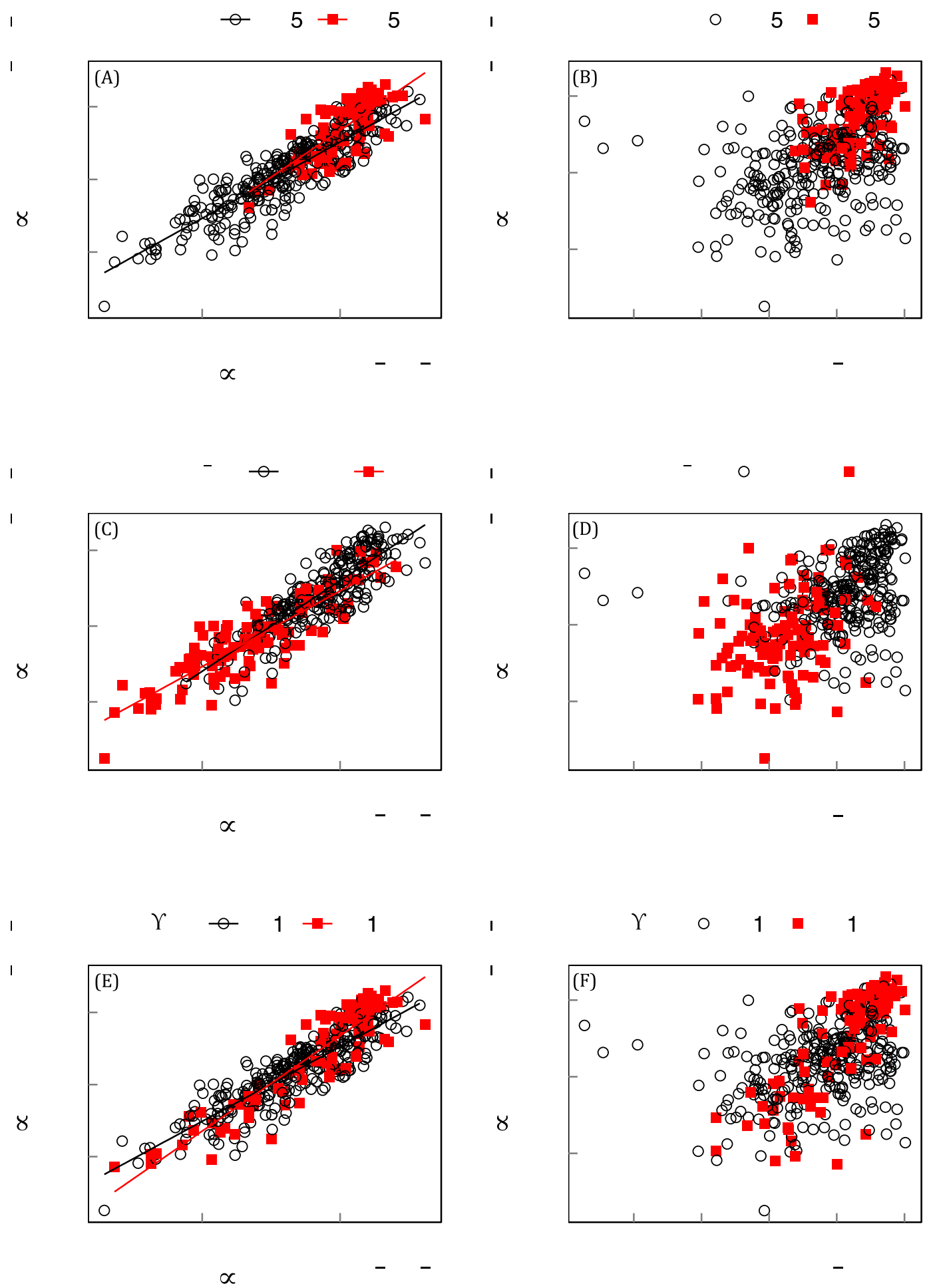

729 Fig. 3. Bivariate relationships of $\log _{10} V_{\text {cmax }}$ versus $\log _{10} J_{\text {max }}$ and $\log _{10} V_{\text {cmax }}$ versus

$730 \log _{10} N_{\text {area }}$, within groups defined by high and low values of climate variables ( $3 \mathrm{~A}$ and 731 3B: MI; 3C and 3D: mPAR; 3E and 3F: MAT) $(n=431)$. Only significant linear 732 regressions $(p<0.05)$ are shown. 
dynamic roles $\bigcirc$ climax $\square$ large pioneer $\square$ small pioneer $\bullet$ subcanopy

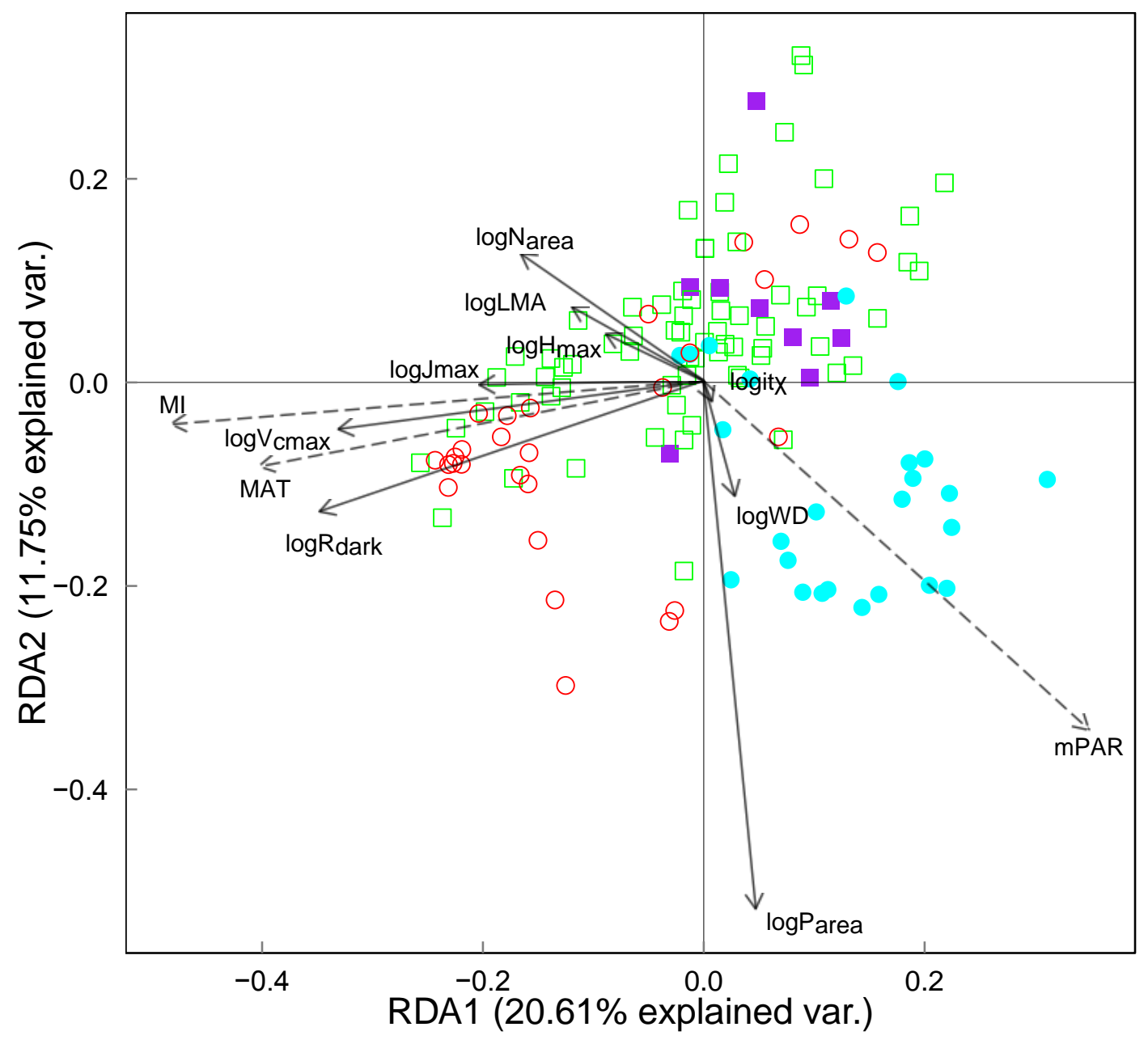

Fig. 4. Redundancy analysis (RDA) of nine traits constrained by climate variables

737 Mean annual temperature (MAT, ${ }^{\circ} \mathrm{C}$ ), the square root of Moisture Index (MI, ratio of

738 precipitation to equilibrium evapotranspiration) and mean monthly photosynthetic

739 active radiation (mPAR, $\left.\mathrm{mol} \mathrm{m}^{-2}\right)(n=130, p<0.05)$. Dynamic roles do not

740 participate in this RDA calculation and are shown for visual comparison only. 

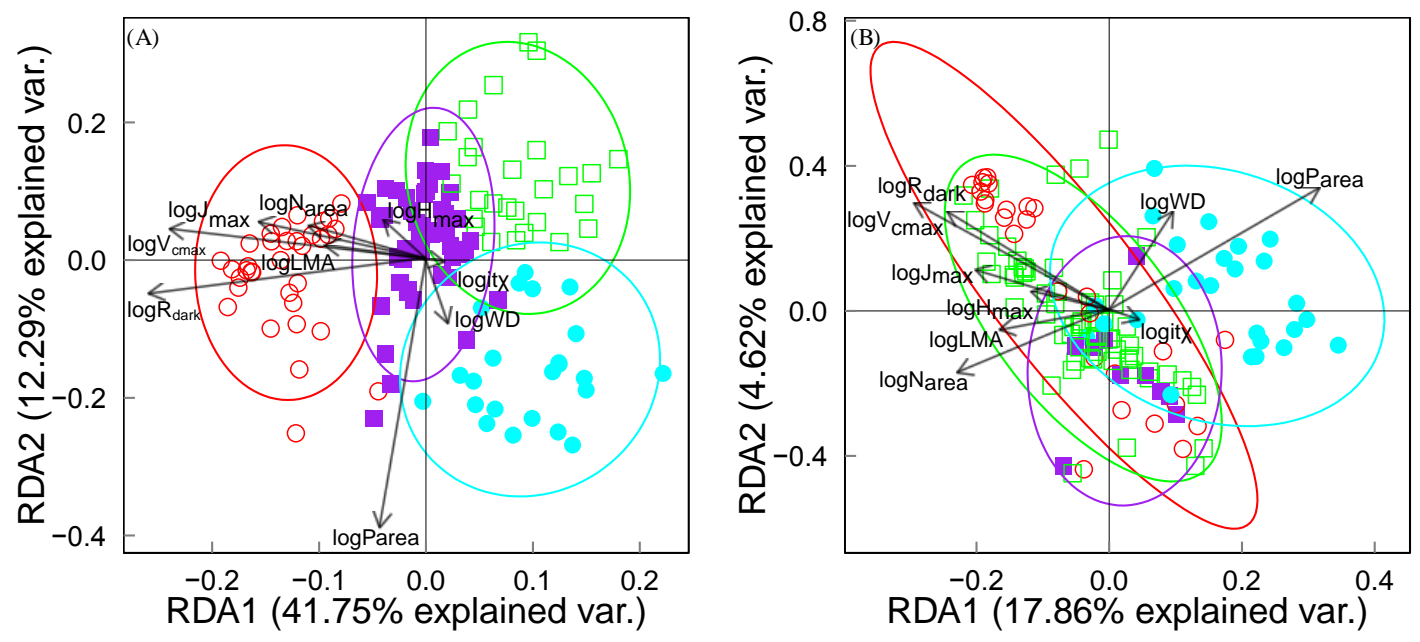

dynamic roles $\ominus$ climax $\square$ large pioneer $-\square$ - small pioneer - - subcanopy

744 Fig. 5. Redundancy analysis (RDA) of nine traits constrained by dynamic roles,

745 defined by quantitative (5A) versus expert (5B) assessment $(n=130)$. Ellipses

746 represent $95 \%$ confidence intervals around the centroid of each group. 


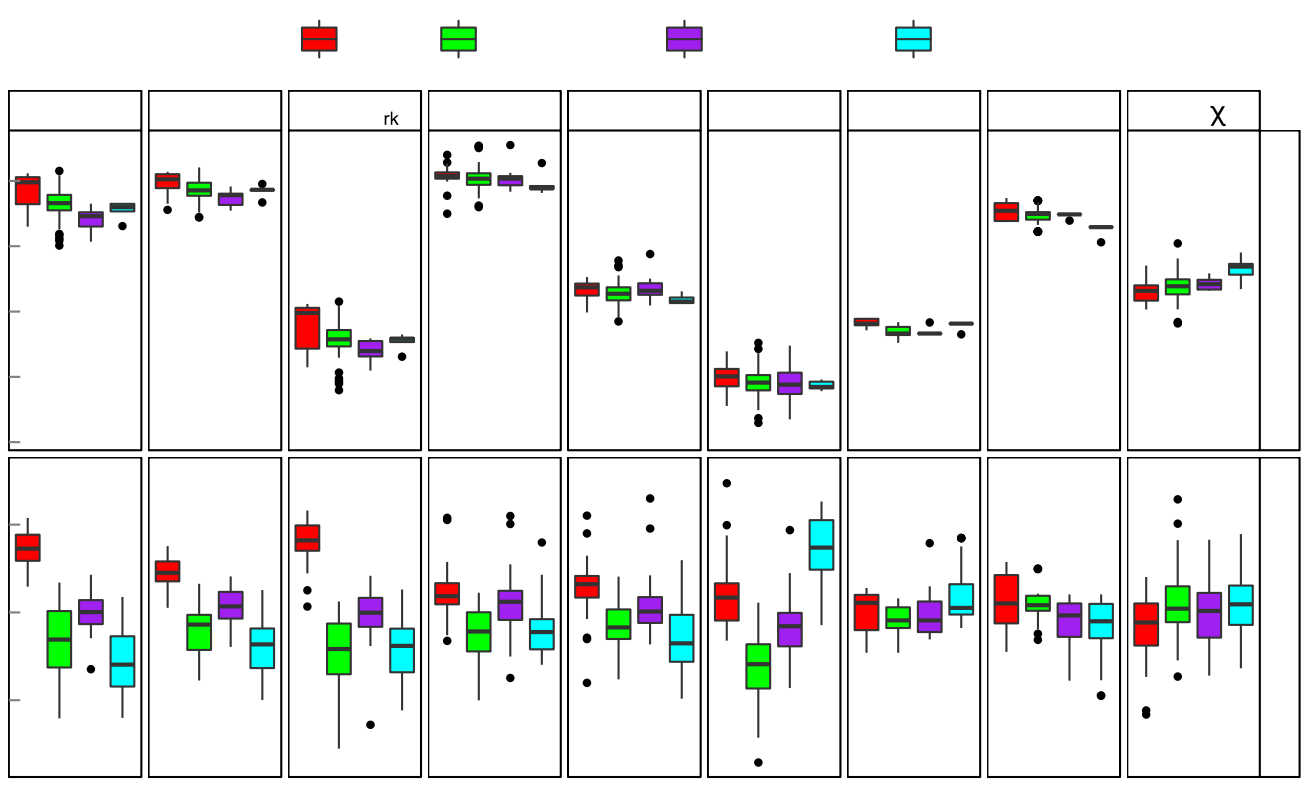

749

750 Fig. 6. Box plots showing means and standard deviation of nine traits according to the

751 four dynamic roles based on quantitative versus expert assessment ( $n=130, p<$

752 0.05). 'Expert' group averages of LMA, $N_{\text {area }}$ land $P_{\text {area }}$ are not significantly different

753 (ANOVA). Dynamic roles of each trait sharing the same letter (Tukey post hoc test)

754 are not significantly different. 

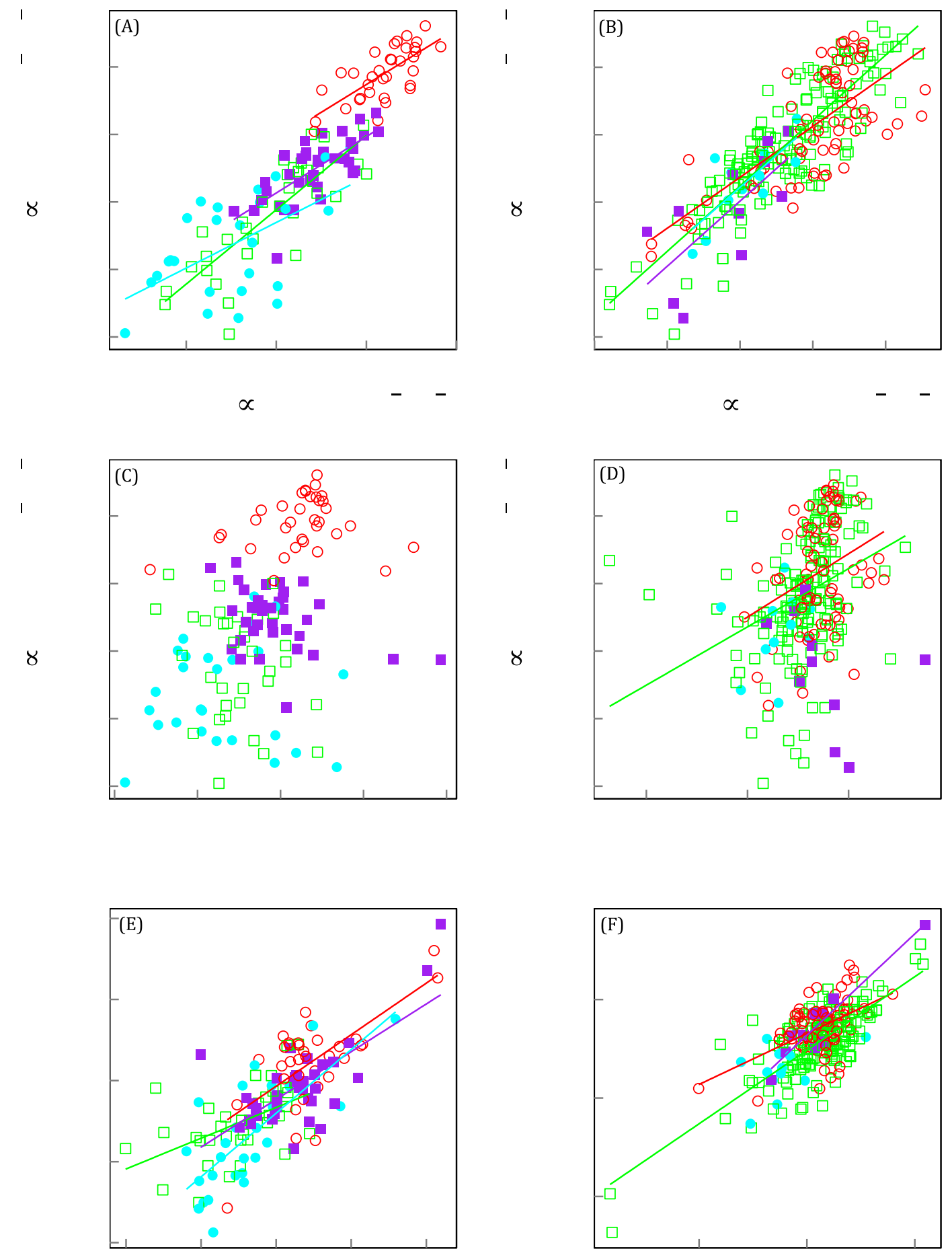

dynamic roles $\neg$

756 Fig. 7. Bivariate relationships of $V_{\text {cmax }}$ versus $J_{\text {max }}, V_{\text {cmax }}$ versus $N_{\text {area }}$ (upper panels) 757 and $N_{\text {area }}$ versus LMA (lower panels) within dynamic role groups, according to 

quantitative (left, $n=130$ ) versus expert (right, $n=262$ ) assessment. Significant linear 759 regressions between $\log _{10}$-transformed variables are shown $(p<0.05)$. 


\section{References}

762

763

764

765

766

767

768

769

770

771

772

773

774

775

776

777

778

779

780

781

782

783

784

785

786

787

788

789

790

791

792

793

794

795

796

797

798

799

800

801

802

803

804

805

806

807

808

809
Allen, S.E., Grimshaw, H., Parkinson, J.A., Quarmby, C., 1974. Chemical analysis of ecological materials. Blackwell Scientific Publications.

Atkin, O.K., Bloomfield, K.J., Reich, P.B., Tjoelker, M.G., Asner, G.P., Bonal, D., Bönisch, G., Bradford, M.G., Cernusak, L.A., Cosio, E.G., Creek, D., Crous, K.Y., Domingues, T.F., Dukes, J.S., Egerton, J.J.G., Evans, J.R., Farquhar, G.D., Fyllas, N.M., Gauthier, P.P.G., Gloor, E., Gimeno, T.E., Griffin, K.L., Guerrieri, R., Heskel, M.A., Huntingford, C., Ishida, F.Y., Kattge, J., Lambers, H., Liddell, M.J., Lloyd, J., Lusk, C.H., Martin, R.E., Maksimov, A.P., Maximov, T.C., Malhi, Y., Medlyn, B.E., Meir, P., Mercado, L.M., Mirotchnick, N., Ng, D., Niinemets, Ü., O'Sullivan, O.S., Phillips, O.L., Poorter, L., Poot, P., Prentice, I.C., Salinas, N., Rowland, L.M., Ryan, M.G., Sitch, S., Slot, M., Smith, N.G., Turnbull, M.H., VanderWel, M.C., Valladares, F., Veneklaas, E.J., Weerasinghe, L.K., Wirth, C., Wright, I.J., Wythers, K.R., Xiang, J., Xiang, S., Zaragoza-Castells, J., 2015. Global variability in leaf respiration in relation to climate, plant functional types and leaf traits. New Phytologist 206, 614-636.

Atkin, O.K., Holly, C., Ball, M.C., 2000. Acclimation of snow gum (Eucalyptus pauciflora) leaf respiration to seasonal and diurnal variations in temperature: the importance of changes in the capacity and temperature sensitivity of respiration. Plant, Cell \& Environment 23, 15-26.

Baraloto, C., Timothy Paine, C., Poorter, L., Beauchene, J., Bonal, D., Domenach, A.M., Hérault, B., Patino, S., Roggy, J.C., Chave, J., 2010. Decoupled leaf and stem economics in rain forest trees. Ecology Letters 13, 1338-1347.

Bernacchi, C.J., Pimentel, C., Long, S.P., 2003. In vivo temperature response functions of parameters required to model RuBP-limited photosynthesis. Plant, Cell \& Environment 26, 1419-1430.

Bernacchi, C.J., Singsaas, E.L., Pimentel, C., Portis Jr, A.R., Long, S.P., 2001. Improved temperature response functions for models of Rubisco-limited photosynthesis. Plant, Cell \& Environment 24, 253-259.

Bloomfield, K.J., Domingues, T.F., Saiz, G., Bird, M.I., Crayn, D.M., Ford, A., Metcalfe, D.J., Farquhar, G.D., Lloyd, J., 2014. Contrasting photosynthetic characteristics of forest vs. savanna species (far North Queensland, Australia). Biogeosciences 11, 7331-7347, https://doi.org/7310.5194/bg-7311-7331-2014.

Botkin, D.B., Janak, J.F., Wallis, J.R., 1972. Some ecological consequences of a computer model of forest growth. The Journal of Ecology, 849-872.

Box, E.O., 1981. Predicting physiognomic vegetation types with climate variables. Vegetatio 45, 127-139.

Bradford, M.G., Metcalfe, D.J., Ford, A., Liddell, M.J., McKeown, A., 2014a. Floristics, stand structure and aboveground biomass of a 25-ha rainforest plot in the wet tropics of Australia. Journal of Tropical Forest Science 26, 543-553.

Bradford, M.G., Murphy, H.T., Ford, A.J., Hogan, D.L., Metcalfe, D.J., 2014b. Longterm stem inventory data from tropical rain forest plots in Australia. Ecology 95, 2362-2000.

Calvin, M., Benson, A.A., 1948. The path of carbon in photosynthesis. US Atomic Energy Commission, Technical Information Division.

Chen, J.-L., Reynolds, J., Harley, P., Tenhunen, J., 1993. Coordination theory of leaf nitrogen distribution in a canopy. Oecologia 93, 63-69.

De Kauwe, M.G., Lin, Y.-S., Wright, I.J., Medlyn, B.E., Crous, K.Y., Ellsworth, D.S., Maire, V., Prentice, I.C., Atkin, O.K., Rogers, A., Niinemets, Ü., Serbin, S.P., Meir, P., Uddling, J., Togashi, H.F., Tarvainen, L., Weerasinghe, L.K., Evans, B.J., Ishida, F.Y., 
Domingues, T.F., 2016. A test of the 'one-point method' for estimating maximum carboxylation capacity from field-measured, light-saturated photosynthesis. New Phytologist 210, 1130-1144.

Denslow, J.S., 1987. Tropical rainforest gaps and tree species diversity. Annual Review of Ecology and Systematics 18, 431-451. insights into the covariation of stomatal, mesophyll and hydraulic conductances from optimization models incorporating nonstomatal limitations to photosynthesis. New Phytologist 217, 571-585.

Díaz, S., Cabido, M., 1997. Plant functional types and ecosystem function in Domingues, T.F., Meir, P., Feldpausch, T.R., Saiz, G., Veenendaal, E.M., Schrodt, F., Bird, M., Djagbletey, G., Hien, F., Compaore, H., Diallo, A., Grace, J., Lloyd, J.O.N., 2010. Co-limitation of photosynthetic capacity by nitrogen and phosphorus in West Africa woodlands. Plant, Cell \& Environment 33, 959-980.

Dong, N., Prentice, I.C., Evans, B.J., Caddy-Retalic, S., Lowe, A.J., Wright, I.J., 2017. Leaf nitrogen from first principles: field evidence for adaptive variation with climate. Biogeosciences 14, 481-495.

Enquist, B.J., Bentley, L.P., 2012. Land plants: new theoretical directions and empirical prospects. Metabolic Ecology: A Scaling Approach. Hoboken, NJ: WileyBlackwell, 164-187.

Evans, J., 1989. Photosynthesis and nitrogen relationships in leaves of $\mathrm{C}_{3}$ plants. Oecologia 78, 9-19.

Farquhar, G.D., von Caemmerer, S., Berry, J.A., 1980. A biochemical model of photosynthetic CO2 assimilation in leaves of C3 species. Planta 149, 78-90.

Fisher, R., Muszala, S., Verteinstein, M., Lawrence, P., Xu, C., McDowell, N., Knox, R., Koven, C., Holm, J., Rogers, B., 2015. Taking off the training wheels: the properties of a dynamic vegetation model without climate envelopes, CLM4.5(ED) Geoscientific Model Development 8, 3593-3619.

Friend, A., Schugart, H., Running, S., 1993. A physiology-based gap model of forest dynamics. Ecology 74, 792-797.

Fyllas, N., Gloor, E., Mercado, L., Sitch, S., Quesada, C., Domingues, T., Galbraith, D., Torre-Lezama, A., Vilanova, E., Ramírez-Angulo, H., 2014. Analysing Amazonian forest productivity using a new individual and trait-based model (TFS v. 1). Geoscientific Model Development 7, 1251-1269.

Fyllas, N.M., Patino, S., Baker, T., Bielefeld Nardoto, G., Martinelli, L., Quesada, C., Paiva, R., Schwarz, M., Horna, V., Mercado, L., 2009. Basin-wide variations in foliar properties of Amazonian forest: phylogeny, soils and climate. Biogeosciences 6, 2677-2708.

Fyllas, N.M., Quesada, C.A., Lloyd, J., 2012. Deriving Plant Functional Types for Amazonian forests for use in vegetation dynamics models. Perspectives in Plant Ecology, Evolution and Systematics 14, 97-110.

Hancock, P., Hutchinson, M., 2006. Spatial interpolation of large climate data sets using bivariate thin plate smoothing splines. Environmental Modelling \& Software 21, 1684-1694.

Harris, I., Jones, P.D., Osborn, T.J., Lister, D.H., 2014. Updated high-resolution grids of monthly climatic observations - the CRU TS3.10 Dataset. International Journal of Climatology 34, 623-642. 
Harrison, S.P., Prentice, I.C., Barboni, D., Kohfeld, K.E., Ni, J., Sutra, J.P., 2010. Ecophysiological and bioclimatic foundations for a global plant functional classification. Journal of Vegetation Science 21, 300-317.

Haxeltine, A., Prentice, I.C., 1996. A General Model for the Light-Use Efficiency of Primary Production. Functional Ecology 10, 551-561.

Hirose, T., Werger, M.J., 1987. Nitrogen use efficiency in instantaneous and daily photosynthesis of leaves in the canopy of a Solidago altissima stand. Physiologia Plantarum 70, 215-222.

Hutchinson, M., 2014a. Daily maximum precipitation: ANUClimate 1.0, 0.01 degree, Australian Coverage, 1970-2012.

Hutchinson, M., 2014b. Daily minimum temperature: ANUClimate 1.0, 0.01 degree, Australian Coverage, 1970-2012.

Hutchinson, M., 2014c. Daily precipitation: ANUClimate 1.0, 0.01 degree, Australian Coverage, 1970-2012.

Koch, G.W., Sillett, S.C., Antoine, M.E., Williams, C.B., 2015. Growth maximization trumps maintenance of leaf conductance in the tallest angiosperm. Oecologia 177, 321-331.

Köppen, W.P., 1931. Grundriss der klimakunde. Walter de Gruyter Berlin.

Kortschak, H.P., Hartt, C.E., Burr, G.O., 1965. Carbon dioxide fixation in sugarcane leaves. Plant Physiology 40, 209.

Langan, L. , Higgins, S. I. and Scheiter, S., 2017. Climate - biomes, pedo - biomes or pyro-biomes: which world view explains the tropical forest-savanna boundary in South America? Journal of Biogeography, 44: 2319-2330.

Lavorel, S., Garnier, E., 2002. Predicting changes in community composition and ecosystem functioning from plant traits: revisiting the Holy Grail. Functional Ecology 16, 545-556.

Legendre, P., Anderson, M.J., 1999. Distance - based redundancy analysis: testing multispecies responses in multifactorial ecological experiments. Ecological Monographs 69, 1-24.

Li, G., Harrison, S.P., Prentice, I.C., Falster, D., 2014. Simulation of tree-ring widths with a model for primary production, carbon allocation, and growth. Biogeosciences 11, 6711-6724.

Liddell, M., 2013a. Cape Tribulation OzFlux tower site OzFlux: Australian and New Zealand Flux Research and Monitoring TERN hdl: 102.100.100/14242. Liddell, M., 2013b. Robson Creek OzFlux tower site OzFlux: Australian and New Zealand Flux Research and Monitoring. TERN hdl: 102.100.100/14243.

Lin, Y.-S., Medlyn, B.E., De Kauwe, M.G., Ellsworth, D.S., 2013. Biochemical photosynthetic responses to temperature: how do interspecific differences compare with seasonal shifts? Tree Physiology 33, 793-806.

Lin, Y.-S., Medlyn, B.E., Duursma, R.A., Prentice, I.C., Wang, H., Baig, S., Eamus, D., de Dios, V.R., Mitchell, P., Ellsworth, D.S., de Beeck, M.O., Wallin, G., Uddling, J., Tarvainen, L., Linderson, M.-L., Cernusak, L.A., Nippert, J.B., Ocheltree, T.W., Tissue, D.T., Martin-StPaul, N.K., Rogers, A., Warren, J.M., De Angelis, P., Hikosaka, K., Han, Q., Onoda, Y., Gimeno, T.E., Barton, C.V.M., Bennie, J., Bonal, D., Bosc, A., Low, M., Macinins-Ng, C., Rey, A., Rowland, L., Setterfield, S.A., Tausz-Posch, S., Zaragoza-Castells, J., Broadmeadow, M.S.J., Drake, J.E., Freeman, M., Ghannoum, O., Hutley, L.B., Kelly, J.W., Kikuzawa, K., Kolari, P., Koyama, K., Limousin, J.-M., Meir, P., Lola da Costa, A.C., Mikkelsen, T.N., Salinas, N., Sun, W., Wingate, L., 2015. 
Optimal stomatal behaviour around the world. Nature Climate Change 5, 459464.

Lloyd, J., Bloomfield, K., Domingues, T.F., Farquhar, G.D., 2013. Photosynthetically relevant foliar traits correlating better on a mass vs an area basis: of ecophysiological relevance or just a case of mathematical imperatives and statistical quicksand? New Phytologist 199, 311-321.

Lombardozzi, D.L., Smith, N.G., Cheng, S.J., Dukes, J.S., Sharkey, T.D., Rogers, A., Fisher, R. and Bonan, G.B., 2018. Triose phosphate limitation in photosynthesis models reduces leaf photosynthesis and global terrestrial carbon storage. Environmental Research Letters 13(7), 074025.

Maire, V., Martre, P., Kattge, J., Gastal, F., Esser, G., Fontaine, S., Soussana, J.-F., 2012. The coordination of leaf photosynthesis links $\mathrm{C}$ and $\mathrm{N}$ fluxes in $\mathrm{C} 3$ plant species. PLoS ONE 7, e38345.

Medlyn, B.E., Duursma, R.A., Eamus, D., Ellsworth, D.S., Prentice, I.C., Barton, C.V.M., Crous, K.Y., De Angelis, P., Freeman, M., Wingate, L., 2011. Reconciling the optimal and empirical approaches to modelling stomatal conductance. Global Change Biology 17, 2134-2144.

Medvigy, D., Wofsy, S.C., Munger, J.W., Hollinger, D.Y., Moorcroft, P.R., 2009. Mechanistic scaling of ecosystem function and dynamics in space and time: Ecosystem Demography model version 2. Journal of Geophysical Research: Biogeosciences 114, 0148-0227.

Meng, T., Wang, H., Harrison, S., Prentice, I., Ni, J., Wang, G., 2015. Responses of leaf traits to climatic gradients: adaptive variation versus competitional shifts. Biogeosciences 12, 5339-5352.

Miyazawa, Y., Kikuzawa, K., 2006. Physiological basis of seasonal trend in leaf photosynthesis of five evergreen broad-leaved species in a temperate deciduous forest. Tree Physiology 26, 249-256.

Moorcroft, P.R., Hurtt, G.C., Pacala, S.W., 2001. A method for scaling vegetation dynamics: The Ecosystem Demography Model (ED). Ecological Monographs 71, 557-586.

Niinemets, Ü., Tenhunen, J.D., 1997. A model separating leaf structural and physiological effects on carbon gain along light gradients for the shade-tolerant species Acer saccharum. Plant, Cell \& Environment 20, 845-866.

Oksanen, J., Blanchet, F.G., Kindt, R., Legendre, P., Minchin, P.R., O'Hara, R., Simpson, G.L., Solymos, P., Stevens, M.H.H., Wagner, H., 2015. Package 'vegan'. Community ecology package, version, 2.2-1.

Olson, M.E., Anfodillo, T., Rosell, J.A., Petit, G., Crivellaro, A., Isnard, S., León Gómez, C., Alvarado - Cárdenas, L.O., Castorena, M., 2014. Universal hydraulics of the flowering plants: vessel diameter scales with stem length across angiosperm lineages, habits and climates. Ecology Letters 17, 988-997.

Pavlick, R., Drewry, D.T., Bohn, K., Reu, B., Kleidon, A., 2013. The Jena DiversityDynamic Global Vegetation Model (JeDi-DGVM): a diverse approach to representing terrestrial biogeography and biogeochemistry based on plant functional trade-offs. Biogeosciences 10, 4137-4177.

Peres-Neto, P.R., Legendre, P., Dray, S., Borcard, D., 2006. Variation partitioning of species data matrices: estimation and comparison of fractions. Ecology 87, 2614-2625.

Prentice, I., Leemans, R., 1990. Pattern and process and the dynamics of forest structure: a simulation approach. The Journal of Ecology, 340-355. 

S., Smith, B., Sykes, M.T., 2007. Dynamic global vegetation modeling: quantifying terrestrial ecosystem responses to large-scale environmental change, Terrestrial ecosystems in a changing world. In: Canadell J.G., Pataki D.E., Pitelka L.F. (eds) Terrestrial Ecosystems in a Changing World. Global Change - The IGBP Series. Springer, Berlin, Heidelberg, pp. 175-192.

961 Prentice, I.C., Cowling, S.A., 2013. Dynamic global vegetation models, in: Levin, 962 S.A., Academic Press (Ed.), Encyclopedia of Biodiversity, 2nd edition ed, pp. 607689.

Prentice, I.C., Cramer, W., Harrison, S.P., Leemans, R., Monserud, R.A., Solomon, A.M., 1992. A global biome model based on plant physiology and dominance, soil properties and climate. Journal of Biogeography 19, 117-134.

Prentice, I.C., Dong, N., Gleason, S.M., Maire, V., Wright, I.J., 2014. Balancing the costs of carbon gain and water transport: testing a new theoretical framework for plant functional ecology. Ecology Letters 17, 82-91.

Prentice, I.C., Liang, X., Medlyn, B.E., Wang, Y.P., 2015. Reliable, robust and realistic: the three $\mathrm{R}$ 's of next-generation land-surface modelling. Atmospheric Chemistry and Physics 15, 5987-6005.

Prentice, I.C., Liddell, M., Furstenau Togashi, H., Atkin, O., Weerasinghe, L., 2013. Leaf Level Physiology, Chemistry and Structural Traits, Far North Queensland SuperSite, Robson Creek, 2012. TERN Australian SuperSite Network. http://portal.tern.org.au/leaf-level-physiology-creek-2012 12.

Prentice, I.C., Meng, T., Wang, H., Harrison, S.P., Ni, J., Wang, G., 2011. Evidence of a universal scaling relationship for leaf $\mathrm{CO}_{2}$ drawdown along an aridity gradient. New Phytologist 190, 169-180.

Prentice, I.C., Sykes, M.T., Cramer, W., 1993. A simulation model for the transient effects of climate change on forest landscapes. Ecological Modelling 65, 51-70.

Purves, D.W., Lichstein, J.W., Strigul, N., Pacala, S.W., 2008. Predicting and understanding forest dynamics using a simple tractable model. Proceedings of the National Academy of Sciences 105, 17018.

Quesada, C.A., Phillips, O.L., Schwarz, M., Czimczik, C.I., Baker, T.R., Patino, S., Fyllas, N.M., Hodnett, M.G., Herrera, R., Almeida, S., Alvarez Dávila, E., Arneth, A., Arroyo, L., Chao, K. J., Dezzeo, N., Erwin, T., di Fiore, A., Higuchi, N., Honorio Coronado, E., Jimenez, E. M., Killeen, T., Lezama, A. T., Lloyd, G., López-González, G., Luizão, F. J., Malhi, Y., Monteagudo, A., Neill, D. A., Núñez Vargas, P., Paiva, R., Peacock, J., Peñuela, M. C., Peña Cruz, A., Pitman, N., Priante Filho, N., Prieto, A., Ramírez, H., Rudas, A., Salomão, R., Santos, A. J. B., Schmerler, J., Silva, N., Silveira, M., Vásquez, R., Vieira, I., Terborgh, J., and Lloyd, J., 2012. Basin-wide variations in Amazon forest structure and function are mediated by both soils and climate. Biogeosciences 9, 2203-2246.

R Core Team, 2012. R: A language and environment for statistical computing. R Foundation for Statistical Computing, Vienna, Austria. http://www.Rproject.org/.

Ranson, S.L., Thomas, M., 1960. Crassulacean Acid Metabolism. Annual Review of Plant Physiology 11, 81-110.

Raunkiær, C., 1934. The Life Forms of Plants and Statistical Plant Geography. Clarendon Press.

Reich, P.B., 2014. The world-wide 'fast-slow' plant economics spectrum: a traits manifesto. Journal of Ecology 102, 275-301. 
1004

1005

1006

1007

1008

1009

1010

1011

1012

1013

1014

1015

1016

1017

1018

1019

1020

1021

1022

1023

1024

1025

1026

1027

1028

1029

1030

1031

1032

1033

1034

1035

1036

1037

1038

1039

1040

1041

1042

1043

1044

1045

1046

1047

1048

1049

1050

1051
Reich, P.B., Walters, M.B., Ellsworth, D.S., 1997. From tropics to tundra: global convergence in plant functioning. Proceedings of the National Academy of Sciences 94, 13730-13734.

Reid, D.E.B., Silins, U., Mendoza, C., Lieffers, V.J., 2005. A unified nomenclature for quantification and description of water conducting properties of sapwood xylem based on Darcy's law. Tree Physiology 25, 993-1000.

Sakschewski, B., Bloh, W., Boit, A., Rammig, A., Kattge, J., Poorter, L., Peñuelas, J., Thonicke, K., 2015. Leaf and stem economics spectra drive diversity of functional plant traits in a dynamic global vegetation model. Global Change Biology 21, 2711-2725.

Scheiter, S., Langan, L., Higgins, S.I., 2013. Next - generation dynamic global vegetation models: learning from community ecology. New Phytologist 198, 957969.

Sharkey, T.D., Bernacchi, C.J., Farquhar, G.D., Singsaas, E.L., 2007. Fitting photosynthetic carbon dioxide response curves for $\mathrm{C}_{3}$ leaves. Plant, Cell \& Environment 30, 1035-1040.

Shugart, H.H., 1984. A Theory of Forest Dynamics. Springer-Verlag, New York.

Sitch, S., Smith, B., Prentice, I.C., Arneth, A., Bondeau, A., Cramer, W., Kaplan, J.O., Levis, S., Lucht, W., Sykes, M.T., Thonicke, K., Venevsky, S., 2003. Evaluation of ecosystem dynamics, plant geography and terrestrial carbon cycling in the LPJ dynamic global vegetation model. Global Change Biology 9, 161-185.

Smith, B., Prentice, I.C., Sykes, M.T., 2001. Representation of vegetation dynamics in the modelling of terrestrial ecosystems: comparing two contrasting approaches within European climate space. Global Ecology and Biogeography 10, 621-637.

Sperry, John S., 2003. Evolution of water transport and xylem structure. International Journal of Plant Sciences 164, S115-S127.

Swaine, M., Whitmore, T., 1988. On the definition of ecological species groups in tropical rain forests. Vegetatio 75, 81-86.

Ter Braak, C.J., Prentice, I.C., 1988. A theory of gradient analysis. Advances in Ecological Research 18, 271-317.

Togashi, H.F., Prentice, I.C., Atkin, O.K., Macfarlane, C., Prober, S., Bloomfield, K.J., Evans, B., 2017. Thermal acclimation of leaf photosynthetic traits in an evergreen woodland, consistent with the co-ordination hypothesis. Biogeosciences Discuss., https://doi.org/10.5194/bg-2017-449, in review, 2017.

Togashi, H.F., Prentice, I.C., Evans, B.J., Forrester, D.I., Drake, P., Feikema, P., Brooksbank, K., Eamus, D., Taylor, D., 2015. Morphological and moisture availability controls of the leaf area-to-sapwood area ratio: analysis of measurements on Australian trees. Ecology and Evolution 5, 1263-1270.

Turner, I.M., 2001. The Ecology of Trees in the Tropical Rain Forest. Cambridge University Press.

Tyree, M.T., Ewers, F.W., 1991. The hydraulic architecture of trees and other woody plants. New Phytologist 119, 345-360.

van Bodegom, P.M., Douma, J.C., Verheijen, L.M., 2014. A fully traits-based approach to modeling global vegetation distribution. Proceedings of the National Academy of Sciences 111, 13733.

Verheijen, L., Brovkin, V., Aerts, R., Bönish, G., Cornelissen, J., Kattge, J., Reich, P., Wright, I., Van Bodegom, P., 2013. Impacts of trait variation through observed 
trait-climate relationships o performance of a representative Earth System Model: a conceptual analysis. Biogeosciences 10, 5497-5515.

Wang, H., Harrison, S.P., Prentice, I.C., Yang, Y., Bai, F., Togashi, H.F., Wang, M., Zhou, S., Ni, J., 2018. The China Plant Trait Database: toward a comprehensive regional compilation of functional traits for land plants. Ecology 99, 500-500.

Wang, H., Prentice, I.C., Keenan, T.F., Davis, T.W., Wright, I.J., Cornwell, W.K., Evans, B.J., Peng, C., 2017. Towards a universal model for carbon dioxide uptake by plants. Nature Plants 3, 734-741.

Warton, D.I., Wright, I.J., Falster, D.S., Westoby, M., 2006. Bivariate line - fitting methods for allometry. Biological Reviews 81, 259-291.

Weerasinghe, L.K., Creek, D., Crous, K.Y., Xiang, S., Liddell, M.J., Turnbull, M.H., Atkin, O.K., 2014. Canopy position affects the relationships between leaf respiration and associated traits in a tropical rainforest in Far North Queensland. Tree Physiology 34, 564-584.

Whitehead, D., Edwards, W.R.N., Jarvis, P.G., 1984. Conducting sapwood area, foliage area, and permeability in mature trees of Picea sitchensis and Pinus contorta. Canadian Journal of Forest Research 14, 940-947.

Whitmore, T., 1982. On pattern and process in forests. In: Newman, E. I. (ed.), The plant community as a working mechanism. pp. 45-59. Blackwell, Oxford. Wickham, H., 2010. ggplot2: Elegant Graphics for Data Analysis. Springer. Woodward, F.I., 1987. Climate and Plant Distribution. Cambridge University Press.

Wright, I.J., Reich, P.B., Westoby, M., Ackerly, D.D., Baruch, Z., Bongers, F., Cavender-Bares, J., Chapin, T., Cornelissen, J.H.C., Diemer, M., Flexas, J., Garnier, E., Groom, P.K., Gulias, J., Hikosaka, K., Lamont, B.B., Lee, T., Lee, W., Lusk, C., Midgley, J.J., Navas, M.-L., Niinemets, U., Oleksyn, J., Osada, N., Poorter, H., Poot, P., Prior, L., Pyankov, V.I., Roumet, C., Thomas, S.C., Tjoelker, M.G., Veneklaas, E.J., Villar, R., 2004. The worldwide leaf economics spectrum. Nature 428, 821-827. Yang, Y. , Wang, H. , Harrison, S.P., Prentice, I.C., Wright, I.J., Peng, C., Lin, G., 2018. Quantifying leaf - trait covariation and its controls across climates and biomes. New Phytologist (online). doi:10.1111/nph.15422

Zhou, S., Duursma, R.A., Medlyn, B.E., Kelly, J.W. and Prentice, I.C., 2013. How should we model plant responses to drought? An analysis of stomatal and nonstomatal responses to water stress. Agricultural and Forest Meteorology 182, 204-214. 